\title{
Adenosine Monophosphate Binding Stabilizes the KTN Domain of the Shewanella denitrificans Kef Potassium Efflux System
}

Christos Pliotas, ${ }^{\dagger}$ Samuel C. Grayer, ${ }^{\ddagger}$ Silvia Ekkerman, ${ }^{\S}$ Anthony K. N. Chan, ${ }^{\dagger}$ Jess Healy, ${ }^{\ddagger}$ Phedra Marius, ${ }^{\dagger}$ Wendy Bartlett, ${ }^{\S}$ Amjad Khan, ${ }^{\ddagger}$ Wilian A. Cortopassi, ${ }^{\ddagger}$ Shane A. Chandler, ${ }^{\|}$ Tim Rasmussen, ${ }^{\S}$ Justin L. P. Benesch, ${ }^{\Uparrow}$ Robert S. Paton, ${ }^{\ddagger}$ Ti Timothy D. W. Claridge, ${ }^{\ddagger}{ }^{\circ}$ Samantha Miller, Ian R. Booth, ${ }^{*, \S}$ James H. Naismith, ${ }^{* \dagger, \perp, \#, @ @ ~ a n d ~ S t u a r t ~ J . ~ C o n w a y, ~}{ }^{*,+, \nabla}$,

${ }^{\dagger}$ Biomedical Sciences Research Complex, University of St Andrews, North Haugh, St Andrews KY16 9ST, U.K.

${ }^{\ddagger}$ Department of Chemistry, Chemistry Research Laboratory, University of Oxford, Mansfield Road, Oxford OX1 3TA, U.K.

${ }^{\S}$ Medical Sciences and Nutrition, School of Medicine, Foresterhill, Aberdeen AB25 2ZD, U.K.

"Physical \& Theoretical Chemistry Laboratory, Department of Chemistry, University of Oxford, South Parks Road, Oxford OX1 3QZ, U.K.

${ }^{\perp}$ Biotherapy Centre, Sichuan University, Chengdu, China

${ }^{\#} \mathrm{RCaH}$, Rutherford Appleton Laboratory, Harwell Oxford, Didcot OX11 0FA, U.K.

${ }^{\circledR}$ Division of Structural Biology, University of Oxford, Henry Wellcome Building for Genomic Medicine, Old Road Campus, Roosevelt Drive, Headington, Oxford OX3 7BN, U.K.

$\nabla^{\nabla}$ Freiburg Institute for Advanced Studies-FRIAS, Albert-Ludwigs-Universität Freiburg, Albertstrasse 19, 79104 Freiburg, Germany

Supporting Information

ABSTRACT: Ligand binding is one of the most fundamental properties of proteins. Ligand functions fall into three basic types: substrates, regulatory molecules, and cofactors essential to protein stability, reactivity, or enzymesubstrate complex formation. The regulation of potassium ion movement in bacteria is predominantly under the control of regulatory ligands that gate the relevant channels and transporters, which possess subunits or domains that contain Rossmann folds (RFs). Here we demonstrate that adenosine monophosphate (AMP) is bound to both RFs of the dimeric bacterial Kef potassium efflux system (Kef), where it plays a structural role. We conclude that AMP binds with high affinity, ensuring that the site is fully occupied at all times in the cell. Loss of the ability to bind AMP, we demonstrate, causes protein, and likely dimer, instability and consequent loss of function. Kef system function is regulated via the reversible binding of comparatively low-affinity glutathione-based ligands at the interface between the dimer subunits. We propose this interfacial binding site is itself stabilized, at least in part, by AMP binding.

\begin{abstract}
A fundamental property of proteins, by which they express their function in the cell, is the binding of ligands, usually ions or molecules of small mass relative to that of the protein itself. At least three different roles are ascribed to the binding of ligands. (1) The ligand is a substrate or essential cofactor for an enzyme. (2) Ligand binding may be purely regulatory, bringing about changes in protein activity. (3) Ligands may stabilize a protein fold. The roles are not mutually exclusive and can be combined. The activation of ligand-gated channels is usually caused by an allosteric transition upon ligand binding at a point distant from the pore; the changes in the concentration of the ligand may reflect the biological state of either the cell or the environment. Regulation of ion flow is critical throughout biology, and for potassium ions $\left(\mathrm{K}^{+}\right)$, ligand-gated channels and transporters are central to the modulation of cellular $\mathrm{K}^{+}$pools.

In bacteria, both $\mathrm{K}^{+}$channels, which play an important role in $\mathrm{K}^{+}$influx and $\mathrm{K}^{+}$efflux systems that control the response of the
\end{abstract}

bacterial cell to electrophiles, have $\mathrm{K}^{+}$transport and NADbinding (KTN) domains. These domains may be covalently attached to the pore or may be separately expressed entities that form noncovalent associations with the pore. Some are hybrid systems utilizing a combination of KTN domains that are part of the integral pore-forming subunit together with KTN domains expressed separately from an internal start codon on the same mRNA as the pore protein. ${ }^{1,2}$ Another major structural variation is that for the channels (e.g., TrkAH, KtrAB, and MthK) octameric rings of KTN domains modulate ion flux, whereas for the Kef systems, dimeric assemblies dominate the known architectures. A conserved feature of KTN domains is a

Received: April 4, 2017

Revised: June 27, 2017

Published: June 28, 2017 
Rossmann fold, a feature known to be associated with nucleotide binding since its first identification in $\mathrm{NAD}(\mathrm{H})$-binding lactate dehydrogenase. $^{3}$

In Escherichia coli, and most other bacteria, multiple transport systems and channels effect control over the $\mathrm{K}^{+}$pool, including the Kef systems, which are gated by glutathione (GSH) and its electrophilic conjugates (GSX). In Gram-positive bacteria, similar protective systems that employ electrophilic conjugates of other species-specific thiols, ${ }^{4}$ for example, bacillithiol, might exist. $^{5-7}$ Whereas the activity of most $\mathrm{K}^{+}$transport systems causes modulation of the cytoplasmic $\mathrm{pH}$ in the alkaline direction, the Kef systems cause acidification in response to cell-damaging electrophiles. ${ }^{8,9}$ The $\sim 600$-residue Kef proteins form dimers of an $~ 380$-amino acid membrane domain, which may contain up to 12 transmembrane spans, although these are poorly defined from a structural perspective. A short hydrophilic linker (20-26 amino acids) connects the membrane domain to two further domains: an 150 -residue KTN domain and a further, less well-conserved, domain of variable length at the extreme C-terminus of the protein. The KTN domains of separate proteins dimerize, and the interface between them contains the GSH-binding site. Gating of the $\mathrm{K}^{+}$efflux system requires GSH/GSX ligand-mediated communication between the C-terminal domains and the loop containing the ion flowregulating HALESDIEP sequence. ${ }^{10}$

The Kef proteins can be broadly divided into two classes, those including E. coli KefC and KefB that require an ancillary protein ( $\mathrm{KefF}^{11}$ and KefG for KefC and $\mathrm{KefB}$, respectively) for full function and those, such as that from Shewanella denitrificans, that do not require an ancillary protein. Gating by GSH/GSX is thought to be almost identical in both protein types. Residues in the predicted GSX-binding site of S. denitrificans Kef, identified by sequence alignment and modeling, will likely play roles similar to that of their E. coli KefC counterparts, which were identified by molecular genetic studies and crystallography. The E. coli KefC protein has been difficult to study biochemically because of the instability of the KefF-KefC complex; thus, our studies have focused on the simpler $S$. denitrificans Kef protein. ${ }^{12}$

The Rossmann folds of the KTN domains in the $\mathrm{K}^{+}$uptake systems, TrkAH and KtrAB, have been studied biochemically and shown by crystallography to bind ATP and NADH. ${ }^{13}$ These uptake systems have $\mathrm{K}^{+}$-permeable pores with pseudo-4-fold symmetry to create a pore reminiscent of the classical P-type $\mathrm{K}^{+}$ channels. Twin pores, arising from separate membrane proteins in the dimer, form associations with an octameric assembly of KTN domains. Binding of ATP and/or NADH modulates the conformation of the octameric rings and regulates the opening of the $\mathrm{K}^{+}$-conducting pore. $\mathrm{ADP}$ and $\mathrm{NAD}^{+}$activate the GsuK potassium channel, via its KTN-related RCK domains, whereas $\mathrm{Ca}^{2+}$ serves as an allosteric inhibitor. ${ }^{14}$ In contrast, the structural basis of regulation of other KTN domain-regulated $\mathrm{K}^{+}$channels (e.g., CglK, Kch, and MthK) by nucleotides is poorly understood; although reversible gating by divalent cations has been described for MthK, the role of nucleotide binding in the $\mathrm{RF}$ is unknown. ${ }^{15}$ Similarly, for the GSX-gated Kef systems, the role of the bound nucleotide is unclear.

Previously obtained X-ray crystal structures of the KTN domain of TrkA from Methanocaldococcus jannaschii and the KTN domain of KtrA from Bacillus subtilis have electron density consistent with $\mathrm{NADH}$ bound in the Rossmann fold. ${ }^{13}$ On the basis of these data, a homology model was constructed that had $\mathrm{NADH}$ modeled into the Rossmann fold of Kef of the E. coli KefFC KTN domain. ${ }^{13}$ In subsequent crystallographic studies of the nucleotide pocket of the KTN domain of the E. coli KefFC KTN domains, ${ }^{10}$ it is suggested that $\mathrm{NADH}$ occupies the nucleotide-binding pocket based on the homology model and the presence of this nucleotide in the crystallization liquor, although only density that is consistent with a bound AMP molecule exists. Subsequently, when structures with GSH and GSX were determined, AMP was modeled into the GSH structure, but no density consistent with a nucleotide was observed in the GSX structure (density consistent with sulfate ions was observed in the RF of the GSX structure). ${ }^{16}$ The uncertainty over the identity of the bound ligand and the lack of any insight into the role of the bound nucleotide prompted us to re-examine the system in more detail.

Here we report the structural analysis of the KTN domain from $S$. denitrificans. We have established that both the isolated ligand-binding C-terminal domain (SdKefCTD) and full-length integral membrane protein ( $S d K e f)$ contain AMP when purified after overexpression in E. coli. Differential scanning fluorimetry (DSF, also known as thermal shift) analysis shows that incubation of $S d$ KefCTD with additional AMP results in major stabilizing effects on the protein. $\mathrm{NADH}$, although it cannot displace AMP from the KTN domain, results in some stabilization in DSF studies. In the isolated soluble SdKefCTD KTN domain, introduction of mutations predicted to affect AMP binding led to a lower level of protein expression, consistent with a role for AMP in protein structural integrity. In agreement with this proposal, molecular dynamics simulations indicate a reduced stability of the SdKefCTD domain when AMP was removed. In the full-length protein, the same mutations yielded inactive channels. We propose that AMP is integral to the KTN domain in $S d \mathrm{Kef}$ and is required for the stable and functional Kef dimer complex.

\section{MATERIALS AND METHODS}

Materials. $n$-Dodecyl $\beta$-D-maltopyranoside (DDM) was purchased from Anatrace (www.affymetrix.com). Glutathione (reduced) (GSH), adenosine monophosphate (AMP), nicotinamide adenine dinucleotide $\left(\mathrm{NAD}^{+}\right)$, and reduced nicotinamide adenine dinucleotide $(\mathrm{NADH})$ were ordered from Fisher. Reagents for buffer and other chemicals were purchased from Sigma unless otherwise stated.

The chemicals, $\mathrm{NaH}_{2} \mathrm{PO}_{4}$ and $\mathrm{Na}_{2} \mathrm{HPO}_{4}$, were purchased from Alfa Aesar and BDH Chemicals Ltd., respectively. Glycerol and $\mathrm{NaCl}$ were purchased from Thermo Fisher Scientific Inc. All other chemicals were purchased from Sigma-Aldrich Co. unless otherwise specified. All of the buffers used in the purification procedures were prefiltered through $0.2 \mu \mathrm{m}$ pore size filter papers (Sartorius UK Ltd.) under vacuum to remove insoluble precipitates.

Expression and Purification of Kef. The KTN construct, denoted as SdKefQCTD, has been characterized previously and contains residues 391-608 of the full-length $S d$ Kef protein, including the KTN domain, the carboxy-terminal peripheral domain, the highly charged Q-linker connecting the $S d$ KefQCTD with the transmembrane domains, and a peptide corresponding to the regulatory HELEVDIEP loop, with a Cterminal $\mathrm{LEH}_{6}$ tag. ${ }^{12,25}$ The SdKefQCTD construct was transformed into E. coli strain BL21(DE3) (www.bioline.com). Cells were grown in $500 \mathrm{~mL}$ of $\mathrm{LB}$ medium at $37^{\circ} \mathrm{C}$ to an $\mathrm{OD}_{600}$ of $\approx 0.8$. The cultures were cooled to $25^{\circ} \mathrm{C}$ and induced with 1 $\mathrm{mM}$ isopropyl $\beta$-D-1-thiogalactopyranoside (IPTG) for $4 \mathrm{~h}$. The cell pellet was resuspended in lysis buffer, $50 \mathrm{mM}$ Tris- $\mathrm{HCl}$ buffer ( $\mathrm{pH} 7.8$ ), $300 \mathrm{mM} \mathrm{KCl}, 40 \mathrm{mM}$ imidazole, $10 \%$ glycerol, and 1 
mM benzamidine. After disruption of the cells with a French press at $18000 \mathrm{psi}$, the suspension was centrifuged at $4000 \mathrm{~g}$ for 20 min to remove cell debris. The supernatant was then centrifuged at $100000 \mathrm{~g}$ for $1 \mathrm{~h}$. The supernatant was then filtered using 0.45 $\mu \mathrm{m}$ diameter filters and passed through a $25 \mathrm{~mL}$ column containing $0.5 \mathrm{~mL}$ of nickel-nitrilotriacetic acid $\left(\mathrm{Ni}^{2+}-\mathrm{NTA}\right)$ agarose, at $4{ }^{\circ} \mathrm{C}$. The column was washed with $15 \mathrm{~mL}$ of wash buffer, $50 \mathrm{mM}$ Tris- $\mathrm{HCl}$ buffer ( $\mathrm{pH} 7.8$ ), $300 \mathrm{mM} \mathrm{KCl,} 50 \mathrm{mM}$ imidazole, $10 \%$ glycerol, and $1 \mathrm{mM}$ benzamidine, to remove nonspecifically bound proteins and was left at $4{ }^{\circ} \mathrm{C}$ overnight. The next morning, the elution followed with $10 \mathrm{~mL}$ of elution buffer, $50 \mathrm{mM}$ Tris- $\mathrm{HCl}$ buffer ( $\mathrm{pH} 7.8$ ), $300 \mathrm{mM} \mathrm{KCl}$, and 300 $\mathrm{mM}$ imidazole, and $0.5 \mathrm{~mL}$ fractions were collected. The fractions were analyzed by sodium dodecyl sulfate-polyacrylamide gel electrophoresis (SDS-PAGE) and ultraviolet-visible (UV-vis) absorption spectroscopy, and the fractions with the highest protein content from the $\mathrm{Ni}^{2+}$-NTA column were applied to a $120 \mathrm{~mL}$ Superose 6 column (General Electrics Healthcare) equilibrated with buffer containing $50 \mathrm{mM}$ Tris- $\mathrm{HCl}(\mathrm{pH} 7.8)$ and $300 \mathrm{mM} \mathrm{KCl}$. Protein was then eluted at a flow rate of $1 \mathrm{~mL} /$ $\mathrm{min}$. The protein concentration was monitored by absorption at $280 \mathrm{~nm}$. The column was calibrated with Bio-Rad standards. The identity and integrity were confirmed by mass spectrometry (Figure S3).

Alternative Protocol. E. coli strain MJF373 ${ }^{12}$ was used to express the $S d$ KefQCTD protein construct, which is encoded in the pTrcSdKefQCTDH 6 plasmid. ${ }^{12}$ The expression of the $S d$ KefQCTD protein can be induced by addition of IPTG. For recombinant protein expression, the E. coli MJF373 host was first transformed with the pTrcSdKefQCTDH 6 plasmid. The resultant transformant was aerobically cultured in the $2 \times \mathrm{TY}$ medium $[16 \mathrm{~g} / \mathrm{L}$ Oxoid Tryptone (Thermo Fisher Scientific Inc.), $10 \mathrm{~g} / \mathrm{L}$ Oxoid Yeast Extract (Thermo Fisher Scientific Inc.), and $5 \mathrm{~g} / \mathrm{L} \mathrm{NaCl}]$ at $30{ }^{\circ} \mathrm{C}$ with an agitation speed of 180 $\mathrm{rpm}$ in the presence of $100 \mu \mathrm{g} / \mathrm{mL}$ ampicillin (Apollo Scientific Ltd.). When solid medium was required, Bacto Agar (BD) was added to a final concentration of $1.5 \%(\mathrm{w} / \mathrm{v})$ in the $2 \times \mathrm{TY}$ medium. When the bacterial culture reached an optical density of 1.0 at $600 \mathrm{~nm}$, IPTG (Apollo Scientific Ltd.) was added to a final concentration of $0.8 \mathrm{mM}$ to induce expression of the recombinant protein. Bacterial cell pellets were then harvested by centrifugation (F10BCI-6x500y rotor, Avanti J-25 Centrifuge, Beckman Coulter Inc.) at $11305 g$ and $4{ }^{\circ} \mathrm{C}$ after IPTG postinduction for $4 \mathrm{~h}$ and kept at $-80{ }^{\circ} \mathrm{C}$ until protein purification. The $S d$ KefQCTD protein was subsequently purified by immobilized metal affinity chromatography (IMAC) and then size-exclusion chromatography (SEC) at $4{ }^{\circ} \mathrm{C}$.

To prepare a sample for protein purification, the frozen cell pellet $(7.70 \mathrm{~g})$ was first resuspended in extraction buffer. Extraction buffer was prepared by completely dissolving one tablet of SigmaFAST Protease Inhibitor Cocktail Tablet, EDTA Free in $100 \mathrm{~mL}$ of a solution containing $50 \mathrm{mM} \mathrm{NaH} \mathrm{PO}_{4} /$

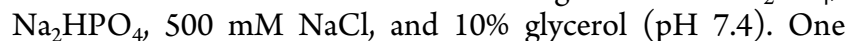
hundred milliliters of extraction buffer per $20 \mathrm{~g}$ of cell mass was used for resuspension. After complete resuspension of the bacterial pellets, the cells were lysed on ice by sonication $(50 \%$ amplitude, $5 \mathrm{~s}$ bursts interrupted by $5 \mathrm{~s}$ pauses for 60 cycles; Ultrasonic Processor, Sonics \& Materials, Inc.) to release cytosolic proteins. Polyethylenimine at a final concentration of $0.15 \%(\mathrm{v} / \mathrm{v})$ was added from a $5 \%(\mathrm{v} / \mathrm{v})$ stock solution ( $\mathrm{pH} 7.4$ ) to the cell lysates, and the mixture was incubated on ice for 15 min to precipitate DNA. Insoluble cell debris and precipitated DNA were removed by centrifugation (JA25.50 rotor, Avanti J-
25 Centrifuge, Beckman Coulter Inc.) at $25000 \mathrm{~g}$ and $4{ }^{\circ} \mathrm{C}$ for 15 $\mathrm{min}$. The resulting supernatant was collected and filtered through $0.45 \mu \mathrm{m}$ pore size syringe filters (Merck Millipore Corp.). The clarified cell lysate was diluted to $100 \mathrm{~mL}$ with extraction buffer and then supplemented with $20 \mathrm{mM}$ imidazole (Sigma-Aldrich Co.) and $10 \mathrm{mM} \beta$-mercaptoethanol (Bio-Rad Laboratories, Inc.) at their final concentrations. This cell lysate preparation was used for the first step of protein purification by IMAC.

For protein purification by IMAC, a HisTrap HP $5 \mathrm{~mL}$ column (GE Healthcare) was used to purify hexahistidine-tagged $S d$ KefQCTD. The affinity purification columns were connected to a computerized ÄKTAFPLC system (GE Healthcare). To equilibrate the column for IMAC, 10 column volumes (CV) of binding buffer $\left[50 \mathrm{mM} \mathrm{NaH} \mathrm{PO}_{4} / \mathrm{Na}_{2} \mathrm{HPO}_{4}, 500 \mathrm{mM} \mathrm{NaCl}\right.$, $10 \%$ glycerol, and $10 \mathrm{mM} \beta$-mercaptoethanol ( $\mathrm{pH} \mathrm{7.4)]} \mathrm{was}$ used. The pretreated cell lysates $(100 \mathrm{~mL}$; from the sample preparation procedure described above) were then loaded into the equilibrated HisTrap HP column. After the sample had been loaded into the column, binding buffer and elution buffer [50 $\mathrm{mM} \mathrm{NaH} \mathrm{PO}_{4} / \mathrm{Na}_{2} \mathrm{HPO}_{4}, 500 \mathrm{mM} \mathrm{NaCl}, 10 \%$ glycerol, and 500 $\mathrm{mM}$ imidazole ( $\mathrm{pH} 7.4)$ ] were mixed in different ratios to wash out nonspecifically bound proteins and elute the protein of interest. First, $10 \mathrm{CV}$ of a step gradient containing 9\% elution buffer (with $45 \mathrm{mM}$ imidazole) and then a linear gradient from 9 to $30 \%$ elution buffer (containing $\leq 150 \mathrm{mM}$ imidazole) over 10 $\mathrm{CV}$ were used to wash out contaminating binders. For elution of the polyhistidine-tagged SdKefQCTD protein, $5 \mathrm{CV}$ of $60 \%$ elution buffer (containing $300 \mathrm{mM}$ imidazole) was used to elute the target in $2 \mathrm{~mL}$ fractions.

After the IMAC purification step, SdKefQCTD was further purified by SEC. The IMAC-purified SdKefQCTD protein was first concentrated by using a Vivaspin sample concentrator (GE Healthcare). The concentrated protein sample $(2 \mathrm{~mL})$ was then loaded via a $2 \mathrm{~mL}$ injection loop into an XK 16/70 gel filtration column (GE Healthcare) packed with $120 \mathrm{~mL}$ of Superdex 75 resin (GE Healthcare). This SEC column was pre-equilibrated with $150 \mathrm{~mL}$ of degassed SEC buffer [50 $\mathrm{mM} \mathrm{NaH} \mathrm{PO}_{4} /$ $\mathrm{Na}_{2} \mathrm{HPO}_{4}$ and $\left.150 \mathrm{mM} \mathrm{NaCl}(\mathrm{pH} \mathrm{7.4})\right]$. The SEC procedure was performed at a constant flow rate $(1 \mathrm{~mL} / \mathrm{min})$ over $150 \mathrm{~mL}$ of a total flow volume, and filtrates were collected in $5 \mathrm{~mL}$ fractions (the sample collection was started at $20 \mathrm{~mL}$ and stopped at $120 \mathrm{~mL}$ ). The SEC-purified protein was further concentrated by a Vivaspin sample concentrator (GE Healthcare) after the purification process. Protein concentrations were determined by a NanoDrop 1000 spectrophotometer (Thermo Fisher Scientific Inc.).

Western Blot of Membrane and Soluble Fractions Containing Full-Length SdKef or SdKefQCTD. Membrane and soluble protein fractions were prepared from MJF373 cells

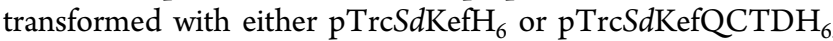
Cells were culture overnight in LK medium ( $10 \mathrm{~g} / \mathrm{L}$ tryptone, 5 $\mathrm{g} / \mathrm{L}$ yeast extract, and $6.4 \mathrm{~g} / \mathrm{L} \mathrm{KCl})$ with ampicillin $(50 \mu \mathrm{g} / \mathrm{mL})$ and diluted the next morning to an $\mathrm{OD}_{650}$ of 0.05 into a fresh $\mathrm{LK}$ medium as a preculture. Once cells had reached an $\mathrm{OD}_{650}$ of 0.4 , they were diluted 10-fold into fresh LK medium and grown again until an $\mathrm{OD}_{650}$ of 0.4 was reached, when $0.3 \mathrm{mM}$ IPTG was added for induction of expression for $30 \mathrm{~min}$, after which $100 \mathrm{~mL}$ of cells was harvested by centrifugation, resuspended in PBS containing a protease inhibitor cocktail tablet (Roche), and lysed by being passed through a French press at 18000 psi. Bulk cell debris was removed by centrifugation for $10 \mathrm{~min}$ at $4{ }^{\circ} \mathrm{C}$ and $4500 \mathrm{~g}$, and membrane (pellet) and soluble fractions (supernatant) were collected after ultracentrifugation at $90000 \mathrm{~g}$ and 4 
${ }^{\circ} \mathrm{C}$ for $60 \mathrm{~min}$. The pellet was suspended in PBS, and Lowry ${ }^{26}$ estimation of the protein concentration was performed on the pellet and supernatant. Samples were separated on 4 to $12 \%$ Invitrogen NuPAGE Bis-Tris gels (ThermoFisher Scientific) run in MES buffer using SeeBlue Plus 2 Marker. Proteins were transferred onto nitrocellulose membranes and probed for expression using an anti-His HRP conjugate antibody (Qiagen). SuperSignal West Dura Extended Duration Substrate (ThermoFisher Scientific) was used for ECL detection of bands, exposed to Amersham Hyperfilm ECL film (GE Healthcare) developed on an M35 X-OMAT processor.

Expression and Purification of the Full-Length SdKef Protein. The full-length membrane protein was transformed into E. coli strain BL21(DE3). Cells were grown the same as they were for $S d$ KefQCTD. The cell pellet was resuspended in $50 \mathrm{mM}$ Tris- $\mathrm{HCl}$ buffer ( $\mathrm{pH} 7.8$ ), $300 \mathrm{mM} \mathrm{KCl}$, and $1 \mathrm{mM}$ benzamidine. After disruption of the cells with a French press at 18000 psi, the suspension was centrifuged at $4000 \mathrm{~g}$ for $20 \mathrm{~min}$ to remove cell debris. The supernatant was then centrifuged at $100000 \mathrm{~g}$ for $1 \mathrm{~h}$. The pellet that contained the cell membrane was solubilized in solubilization buffer [50 mM Tris- $\mathrm{HCl}$ buffer ( $\mathrm{pH} 7.8), 300 \mathrm{mM}$ $\mathrm{KCl}, 1 \mathrm{mM}$ benzamidine, 1.5\% DDM, 10\% glycerol, and $25 \mathrm{mM}$ imidazole] by using a homogenizer and left to gently shake for 1 $\mathrm{h}$ at $4{ }^{\circ} \mathrm{C}$. The solubilized sample was subsequently passed through a $25 \mathrm{~mL}$ column containing $0.5 \mathrm{~mL}$ of nickelnitrilotriacetic acid $\left(\mathrm{Ni}^{2+}-\mathrm{NTA}\right)$ agarose, at $4{ }^{\circ} \mathrm{C}$. The column was washed with $15 \mathrm{~mL}$ of wash buffer $[50 \mathrm{mM}$ Tris- $\mathrm{HCl}$ buffer (pH 7.8), $300 \mathrm{mM} \mathrm{KCl}, 1 \mathrm{mM}$ benzamidine, 0.05\% DDM, and $35 \mathrm{mM}$ imidazole] to remove nonspecifically bound proteins and was left at $4{ }^{\circ} \mathrm{C}$ overnight. The next morning, elution was performed with $10 \mathrm{~mL}$ of elution buffer [ $50 \mathrm{mM}$ Tris- $\mathrm{HCl}$ buffer ( $\mathrm{pH}$ 7.8), $300 \mathrm{mM} \mathrm{KCl}, 0.05 \% \mathrm{DDM}$, and $300 \mathrm{mM}$ imidazole], and $0.5 \mathrm{~mL}$ fractions were collected. The fractions were analyzed by SDS-PAGE and UV-vis absorption spectroscopy, and the highest fractions were applied to a $120 \mathrm{~mL}$ Superose 6 column (General Electrics Healthcare) equilibrated with buffer containing $50 \mathrm{mM}$ Tris- $\mathrm{HCl}$ buffer ( $\mathrm{pH} 7.8$ ), $300 \mathrm{mM} \mathrm{KCl}$, and $0.05 \%$ DDM. Protein was then eluted at a flow rate of $1 \mathrm{~mL} / \mathrm{min}$. The protein concentration was monitored by absorption at $280 \mathrm{~nm}$. The column was calibrated with Bio-Rad standards.

Structural Biology. SdKefQCTD was prone to aggregation over an extended rage of concentrations required for structural studies, but using stirred ultrafiltration cell 8003 with a $30 \mathrm{kDa}$ membrane cutoff (www.millipore.com) and a nitrogen stream at $4{ }^{\circ} \mathrm{C}$ prevented this, allowing a concentration of around $20 \mathrm{mg}$ $\mathrm{mL}^{-1}$, in buffer containing $50 \mathrm{mM}$ Tris- $\mathrm{HCl}(\mathrm{pH} \mathrm{7.8)}$ and 300 $\mathrm{mM} \mathrm{KCl}$. Crystal trials were set up by the hanging drop method on freshly prepared protein samples that have not been previously frozen and involved mixing $1: 1$ and 2:1 protein solution:precipitant volumes equilibrated against a large volume of precipitant. Crystals grew to full size dimensions of $0.2 \mathrm{~mm} \times$ $0.05 \mathrm{~mm} \times 0.05 \mathrm{~mm}$ in $\sim 2.5$ months at $21{ }^{\circ} \mathrm{C}$. The best crystals (judged by visual inspection) were obtained using $0.2 \mathrm{M}$ sodium malonate ( $\mathrm{pH} 7.0)$ and $20 \%(\mathrm{w} / \mathrm{v})$ PEG 3350 as a precipitant. Prior to data collection, crystals were transferred into a solution containing $0.2 \mathrm{M}$ sodium malonate $(\mathrm{pH} 7.0)$ and $40 \%(\mathrm{w} / \mathrm{v})$ PEG 3350. Data were collected at $100 \mathrm{~K}$ on a single crystal, which diffracted to a resolution of $2.92 \AA$ on I24 at Diamond (Oxford, U.K.). Data were indexed, integrated, and merged using MOSFLM/SCALA [Leslie (1992) Joint CCP4 and ESFEAMCB newsletter on protein crystallography, No. 26, pp 1-10] as implemented in CCP4 [CCP4 (1994) Acta Crystallographica Section D 50,760-763]. The resolution limits were determined by the data statistics and the Wilson plot. The CCP4 program POINTLESS was used to assign space groups for Kef as $P 4_{2} 2_{1} 2$. The structure was determined using molecular replacement with the program PHASER using E. coli KefC [Protein Data Bank (PDB) entry $3 \mathrm{EYW}$ ] as a model containing residues $410-570$ (omitting all water molecules and ligands with nonconserved residues set to alanine). AMP was modeled in both monomers, and refinement proceeded by REFMAC5 and manual intervention COOT. Full crystallographic statistics are listed in Table 1.

Table 1. Statistics of the SdKefQCTD X-ray Crystal Structure

\begin{tabular}{|c|c|}
\hline \multicolumn{2}{|c|}{ Data Collection } \\
\hline beamline & Diamond_I24 (21/10/2012) \\
\hline wavelength $(\AA)$ & 0.9686 \\
\hline resolution $(\AA)$ & $3.09(47.6-3.09)$ \\
\hline cell constants & $\begin{array}{l}a=71.6 \AA, b=71.6 \AA, c=140.4 \AA \\
\alpha=\beta=\gamma=90^{\circ}\end{array}$ \\
\hline no. of unique reflections & $6976(399)$ \\
\hline mean $I / \sigma$ & $15.3(1.9)$ \\
\hline completeness (\%) & $97.6(85.8)$ \\
\hline multiplicity & $6.2(3.3)$ \\
\hline$R_{\text {merge }}$ & $0.098(0.651)$ \\
\hline space group & $P 4_{1} 2_{1} 2$ \\
\hline Wilson $B$-factor $\left(\AA^{2}\right)$ & 77 \\
\hline \multicolumn{2}{|c|}{ Refinement } \\
\hline$R(\%)$ & $20.53(29.8)$ \\
\hline$R_{\text {free }}(\%)$ & $26.04(35.5)$ \\
\hline PDB entry & $5 \mathrm{NC} 8$ \\
\hline no. of atoms & 2448 \\
\hline $\begin{array}{l}\text { root-mean-square deviation for bond } \\
\text { lengths }(\AA)\end{array}$ & 0.01 \\
\hline $\begin{array}{l}\text { root-mean-square deviation for bond } \\
\text { angles (deg) }\end{array}$ & 1.558 \\
\hline Molprobity (S10) score & 2.03 (99th percentile) \\
\hline Clashscore, all atoms, score & 5.43 (100th percentile) \\
\hline
\end{tabular}

Ligand Identification. One hundred microliters of $200 \mu \mathrm{M}$ purified SdKefQCTD in $50 \mathrm{mM}$ Tris- $\mathrm{HCl}$ (pH 7.8), $300 \mathrm{mM}$ $\mathrm{KCl}$ buffer and full-length purified $S d \mathrm{Kef}$ in $50 \mathrm{mM}$ Tris- $\mathrm{HCl}$ ( $\mathrm{pH} 7.8$ ), $300 \mathrm{mM} \mathrm{KCl}, 0.05 \%$ DDM buffer were denatured by being subjected to a constant temperature of $95{ }^{\circ} \mathrm{C}$ on a bench thermo block for $30 \mathrm{~min}$. The total volume of the sample containing the denatured protein was loaded on a vivaspin concentrator with a $3 \mathrm{kDa}$ cutoff and centrifuged at full speed on a benchtop centrifuge until all liquid had gone through the membrane $(30 \mathrm{~min})$. The filtrate was loaded on a Superdex Peptide 10/300 column (General Electrics Healthcare) with an optimal size separation from 100 to $7000 \mathrm{Da}$. Prior to sample loading, the column was equilibrated with buffer D. AMP, ATP, and $\mathrm{NADH}$ in volumes of $100 \mu \mathrm{L}$ and at concentrations of $2 \mathrm{mM}$ were individually loaded onto the same column on the same day, under identical conditions to calibrate its behavior. The UV active high-performance liquid chromatography (HPLC) peak was subjected to matrix-assisted laser desorption ionization mass spectrometry, as were the standards.

Nuclear Magnetic Resonance (NMR). NMR experiments were performed at a ${ }^{1} \mathrm{H}$ frequency of 600 or $700 \mathrm{MHz}$ using a Prodigy $\mathrm{BBO}$ probe $(600 \mathrm{MHz})$ or Bruker Avance III spectrometer equipped with a TCI inverse cryoprobe (700 $\mathrm{MHz}$ ), respectively. The samples were prepared in $5 \mathrm{~mm}$ NMR tubes and experiments conducted at listed temperatures. CPMG experiments employed the PROJECT sequence $\left(90^{\circ}{ }_{x}-[\tau-\right.$ 
$\left.180^{\circ}{ }_{y}-\tau-90^{\circ} y-\tau-180^{\circ}{ }_{y}-\tau\right]_{n}-$ acq) as described by Aguilar et al. with a total filter time of $96 \mathrm{~ms} .{ }^{27}$ In all edited ${ }^{1} \mathrm{H}$ experiments, water suppression was achieved by presaturation. Pulse tip angle calibration was performed for all the samples using the Bruker pulsecal routine.

The protein was prepared to a final concentration of $330 \mu \mathrm{M}$ in deuterated sodium phosphate buffer as follows.

The purified protein solution was exchanged with deuterated sodium phosphate buffer $\left[50 \mathrm{mM} \mathrm{NaH} \mathrm{PO}_{4} / \mathrm{Na}_{2} \mathrm{HPO}_{4}\right.$ and 150 $\mathrm{mM} \mathrm{NaCl}(\mathrm{pH} 7.4)$, which were prepared in deuterium oxide] by using PD MiniTrap G-25 columns (GH Healthcare). The exchange was performed by the spin protocol, according to the manufacturer's instructions.

The reference spectra of each of the ligands also were run at a concentration of $330 \mu \mathrm{M}$ in deuterated sodium phosphate buffer [50 mM NaH $\mathrm{PO}_{4} / \mathrm{Na}_{2} \mathrm{HPO}_{4}$ and $150 \mathrm{mM} \mathrm{NaCl}$ (pH 7.4), which were prepared in deuterium oxide].

The protein was denatured on a heat block at $80{ }^{\circ} \mathrm{C}$ for $3 \mathrm{~h}$. Subsequently, the protein precipitate was centrifuged down and the resultant supernatant used directly for NMR studies. The ligands $\mathrm{AMP}, \mathrm{ADP}$, and $\mathrm{NADH}$ were heat treated in the same manner as controls. The experiments were repeated without removing samples from NMR tubes to confirm AMP was not observed from contamination.

Native Mass Spectrometry. Nanoelectrospray (nESI) MS experiments were performed on a QToF-2 mass spectrometer (Waters Corp., Wilmslow, U.K.) with conditions optimized for the transmission of intact noncovalent protein complexes. ${ }^{18}$ The sample was buffer exchanged into $200 \mathrm{mM}$ ammonium acetate and sprayed at a concentration of $7.5 \mu \mathrm{M}$ with respect to the dimer. Experiments were conducted at a positive polarity with the following instrument settings: capillary, $1.4 \mathrm{kV}$; sample cone, $40 \mathrm{~V}$; extraction cone, $25 \mathrm{~V}$; backing pressure, $3.5 \mu$ bar; collision cell pressure, $35 \mu \mathrm{bar}$. The instrument was calibrated using CsI, and data analysis was performed using MassLynx (Waters Corp.) software. Protein masses were determined using the three most intense charge states.

Differential Scanning Fluorimetry. Assays were performed using a Stratagene Mx3005P qPCR instrument (Expt filter set, excitation at $492 \mathrm{~nm}$, emission at $568 \mathrm{~nm}$ ). The initial temperature was set to $25{ }^{\circ} \mathrm{C}$ (held for $5 \mathrm{~min}$ ), increasing in increments of $1{ }^{\circ} \mathrm{C}$ for 55 cycles (held for 90 s per cycle). Stock solutions of the ligands under examination were prepared to a concentration of $100 \mathrm{mM}$ in buffer containing $50 \mathrm{mM}$ sodium phosphate and $150 \mathrm{mM} \mathrm{NaCl}(\mathrm{pH} 7.4)$ [with the exception of (-)-adenosine, which was prepared in dimethyl sulfoxide (DMSO)]. The $100 \mathrm{mM}$ stock solutions were then diluted to a concentration of $10 \mathrm{mM}$ in buffer containing $50 \mathrm{mM}$ sodium phosphate and $150 \mathrm{mM} \mathrm{NaCl}(\mathrm{pH} 7.4)$. A protein master mix was prepared containing SdKefQCTD $(13.3 \mu \mathrm{M})$ and Sypro Orange (2.2×, Invitrogen) in buffer containing $50 \mathrm{mM}$ sodium phosphate and $150 \mathrm{mM} \mathrm{NaCl}(\mathrm{pH} 7.4)$. Ninety-six-well plates (Axygen) were prepared using the protein master mix $(22.5 \mu \mathrm{L}$ per well; final protein concentration of $12 \mu \mathrm{M}$ and final dye concentration of $2 \times)$ and the appropriate ligand $(2.5 \mu \mathrm{L}$ per well; final concentration of $1 \mathrm{mM}$ ). The plate was centrifuged at 1000 $\mathrm{rpm}$ for $3 \mathrm{~min}$ before being run. Controls were performed with dye alone, ligand and dye, and the protein alone. The $T_{M}$ (melting temperature) was identified by fitting to the Boltzmann equation (Prism 5). ${ }^{19}$ The change in unfolding temperature $\left(\Delta T_{\mathrm{M}}\right)$ was calculated as the shift in $T_{\mathrm{M}}$ relative to the $T_{\mathrm{M}}$ of the protein with $2.5 \mu \mathrm{L}$ of buffer [DMSO in the case of $(-)$-adenosine], in the absence of any ligand. A Student's $t$ test was performed to ensure that the changes were statistically significant.

Expression and Purification of Kef Mutant Construct R416E SdKefQCTD. To express SdKefQCTD(R416E), the pTrcSdKefQCTDH ${ }_{6}-\mathrm{R}_{416 \mathrm{E}}$ plasmid was first transformed into E. coli strain MJF373. ${ }^{12}$ The expression and purification conditions were the same as those employed in the alternative protocol for purifying the unmodified SdKefQCTD counterpart, except medium LK $[10 \mathrm{~g} / \mathrm{L}$ Oxoid Tryptone (Thermo Fisher Scientific Inc.), $5 \mathrm{~g} / \mathrm{L}$ Oxoid Yeast Extract (Thermo Fisher Scientific Inc.), $6.4 \mathrm{~g} / \mathrm{L} \mathrm{KCl}$ (Thermo Fisher Scientific Inc.), and $2 \mathrm{~g} / \mathrm{L}$ glucose (Sigma-Aldrich Co.)] and a cell mass of $6.26 \mathrm{~g}$ were used instead for protein expression and protein purification, respectively.

Quantification of the Bound AMP Content in Proteins by HPLC (R416E). Analytical HPLC was performed on a PerkinElmer Flexar system with a binary LC pump and UV-vis LC detector. A Dionex Acclaim 120 column (C18, $5 \mu \mathrm{m}, 120 \AA$, $4.6 \mathrm{~mm} \times 150 \mathrm{~mm}$ ) was used to analyze the AMP content in unmodified $S d$ KefQCTD as well as its mutant counterpart, SdKefQCTD(R416E). This HPLC analytic method had a constant flow rate of $1 \mathrm{~mL} / \mathrm{min}$ and lasted for $20 \mathrm{~min}$ per run. It adopted a mobile phase with a mixture of solvent A (99.9:0.1 $\mathrm{H}_{2} \mathrm{O}$ :formic acid ratio) and solvent $\mathrm{B}$ (99.9:0.1 MeCN:formic acid ratio). This program employed $100 \%$ solvent $A$ during the first minute and then increased the concentration of solvent $B$ from 0 to $100 \%$ over 10 min using a linear gradient, and this $100 \%$ solvent $B$ concentration was held for a further 3 min until the $14 \mathrm{~min}$ had passed. After that, the method decreased the concentration of solvent B to $0 \%$ at $15 \mathrm{~min}$, followed by $100 \%$ solvent A running through the column for the last $5 \mathrm{~min}$ of the experiment. The whole HPLC program is summarized in Figure 1.

\section{HPLC Method}

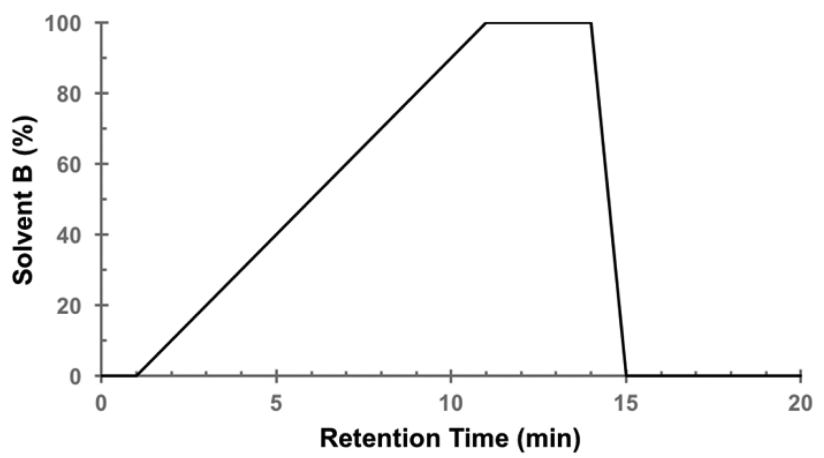

Figure 1. Summary of the HPLC program.

We adopted an experimental procedure similar to that developed by Chen et al. ${ }^{28}$ to analyze the bound AMP molecule in proteins. To release the bound AMP, proteins of defined concentrations $(10 \mu \mathrm{L})$ were first heated at $95^{\circ} \mathrm{C}$ in a dry heating block for $5 \mathrm{~min}$ and then subjected to centrifugation at 13000 rpm for $10 \mathrm{~min}$ (MIKRO 20 Centrifuge, Hettich) to pellet down denatured protein precipitates. The resultant pellet was resuspended in $10 \mu \mathrm{L}$ of SEC buffer $\left[50 \mathrm{mM} \mathrm{NaH} \mathrm{PO}_{4} /\right.$ $\mathrm{Na}_{2} \mathrm{HPO}_{4}$ and $150 \mathrm{mM} \mathrm{NaCl}(\mathrm{pH} \mathrm{7.4)}$ ), and the mixture was then centrifuged at $13000 \mathrm{rpm}$ for $10 \mathrm{~min}$ (MIKRO 20 Centrifuge, Hettich). The resulting supernatants from the two centrifugation steps described above were combined $(10 \mu \mathrm{L}+10$ $\mu \mathrm{L}=20 \mu \mathrm{L})$ and used as an injection sample for subsequent 
$A$

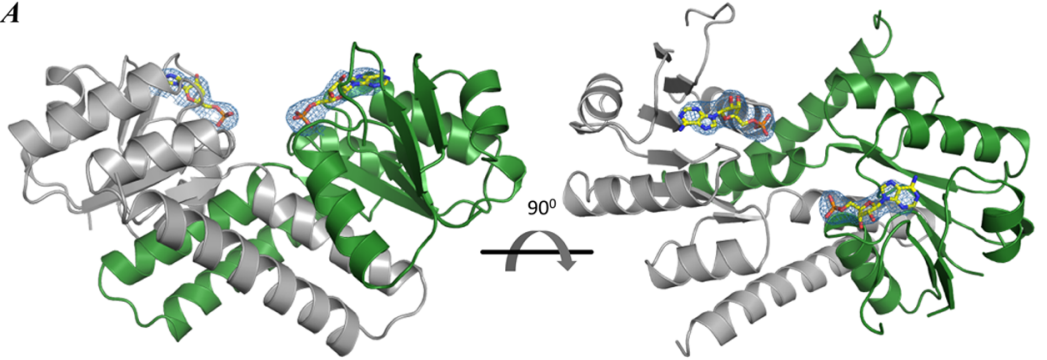

$\boldsymbol{B}$

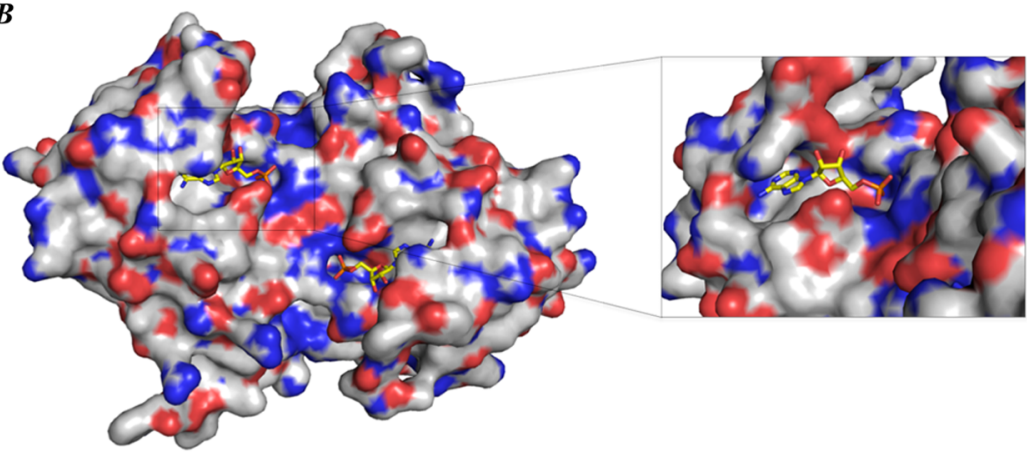

C
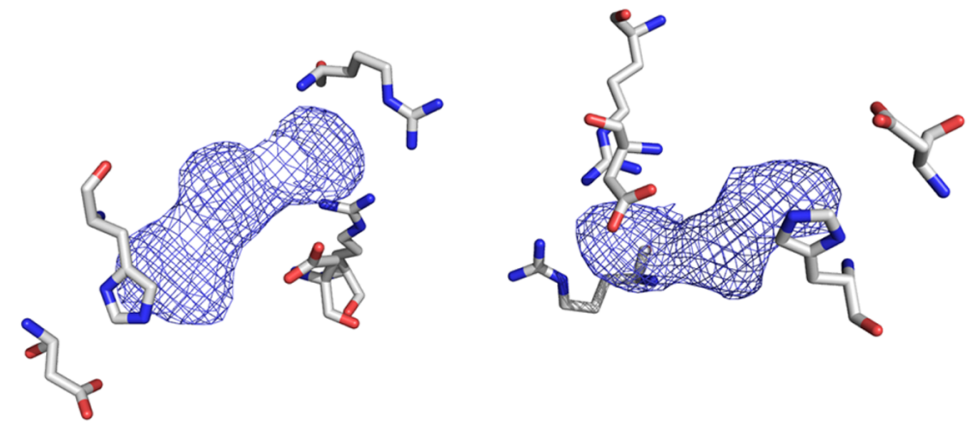

D
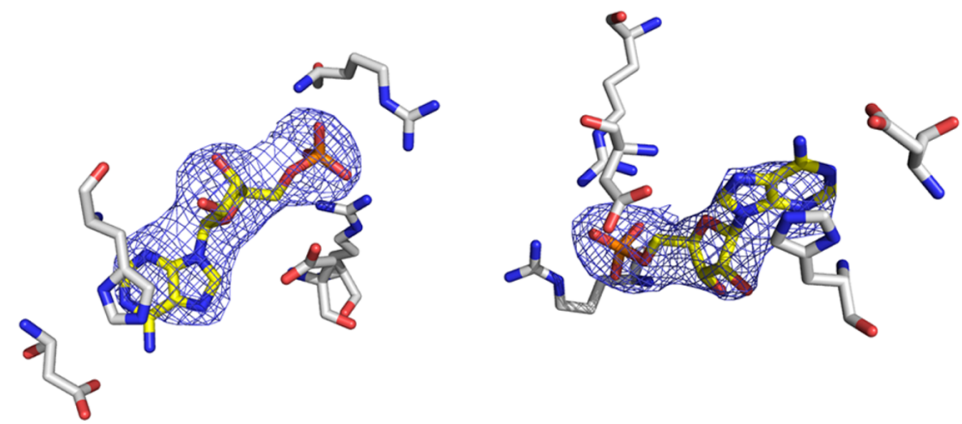

Figure 2. (A) X-ray crystal structure that shows $S d$ KefQCTD as dimeric, with each nucleotide-binding pocket occupied by an AMP molecule (PDB entry 5NC8). (B) View of the Kef protein looking from the membrane, in a surface view. AMP occupies both nucleotide-binding pockets and is depicted as sticks (yellow carbons). (C) Two views of the $F_{\mathrm{o}}-F_{\mathrm{c}}$ electron density map contoured at $3.0 \sigma$. The phases were calculated from a model that had not included AMP. (D) The same $F_{\mathrm{o}}-F_{\mathrm{c}}$ map now with the final position of the AMP molecule shown as sticks.

HPLC analysis. For the spiking HPLC experiments, supernatants from the first centrifugation step $(10 \mu \mathrm{L})$ were combined with AMP solutions $(10 \mu \mathrm{L})$ of defined concentrations.

Computational Methods. Molecular dynamics (MD) simulations were performed using the SdKefQCTD model previously built by Healy and co-workers. ${ }^{1}$ A total of four systems were evaluated: (a) SdKefQCTD with gluthathione (GSH) and two AMP molecules, (b) SdKefQCTD with ESG and two AMP molecules, (c) SdKefQCTD with GSH, and (d) SdKefQCTD with ESG. Molecular mechanics parameters for ESG, GSH, and
AMP were taken from the General AMBER Force Field $(\mathrm{GAFF})^{2}$ with AM1-BCC atomic charges. Hydrogen atoms were removed from amino acid residues using the MolProbity Server $^{2}$ and added using tLeap. ${ }^{3}$ Glutamate and aspartate residues were assigned as negatively charged and lysine and arginine as positively charged. Minimization and MD calculations were performed using AMBER Force Field 12SB within AMBER version 12 with the GPU-accelerated version of PMEMD. ${ }^{4}$ Crystallographic waters were not removed, while the protein was further solvated by a box of TIP-3P water 


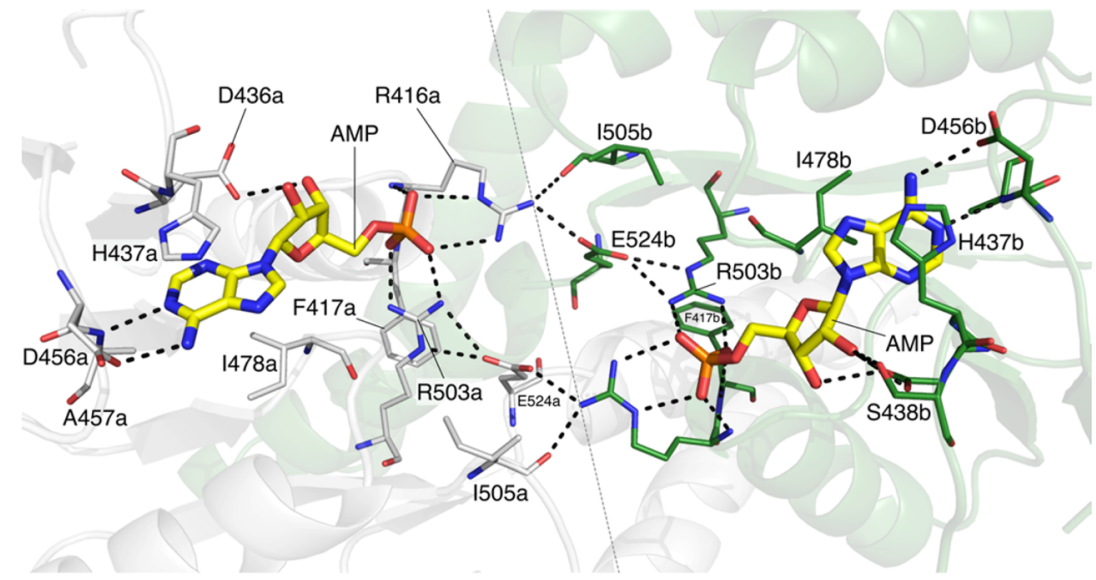

Figure 3. Two AMP-binding pockets of SdKefQCTD from S. denitrificans (PDB entry 5NC8, AMP carbons colored yellow). The key residues involved in AMP binding are highlighted as lines, with the residues from chain a shown with white carbons and the residues from chain $b$ shown with green carbons. The gray dotted line indicates the dimer interface.

molecules. ${ }^{5}$ Simulations were performed in octahedral boxes with an initial volume close to $160 \mathrm{~nm}^{3}$ containing 3060 water molecules, adding countercations $\left(\mathrm{Na}^{+}\right)$to equilibrate the system. Energy minimization was performed in two steps. First, we used steepest descent followed by conjugate gradients during which the initial positions of the small molecule inhibitor and the protein structure obtained after homology modeling were restrained (PR). Second, the same minimization methodology was performed without PR. The minimized macromolecule-small molecule(s) complex was then subjected to equilibration for $500 \mathrm{ps}$ and a production $\mathrm{MD}$ simulation for 40 $\mathrm{ns}$ in the NPT ensemble using a Langevin thermostat to simulate a constant temperature at $310 \mathrm{~K}\left(\tau_{T}=0.1 \mathrm{ps}\right)$. Previous work performed by Zou, ${ }^{6}$ Hong, ${ }^{7}$ Shiao, ${ }^{8}$ and Gewert ${ }^{9}$ and their coworkers showed that nanoscale $\mathrm{MD}$ could be enough to achieve reasonable protein models obtained by homology modeling. Isotropic position scaling was used to maintain a pressure of 1 atm $\left(\tau_{p}=2 \mathrm{ps}\right) .{ }^{10} \mathrm{MD}$ simulation was performed using a $1 \mathrm{fs}$ integration time and a nonbonding cutoff of $8 \AA$, with the Shake algorithm ${ }^{11}$ turned on to constrain bonds involving hydrogen. A total of 2000 snapshots were obtained at intervals of 20 ps in producing plots of the geometric variation during the simulation.

\section{RESULTS}

X-ray Crystal Structure of the C-Terminal Domain of Kef from S. denitrificans (SdKefQCTD). A construct of $S$. denitrificans KTN carboxy-terminal domains (SdKefQCTD) was previously created to optimize stability and solubility. ${ }^{12}$ The protein was purified to homogeneity from E. coli BL21(DE3) and crystallized. So as not to bias the occupancy of the Rossmann fold, no nucleotide was added before, during, or after purification or crystallization of the sample used for all crystallization trials. Therefore, the presence of AMP in the crystal has arisen from nucleotide binding inside the $E$. coli cell and subsequent copurification. Optimization of initial sparse matrix crystallization conditions yielded a single crystal for which diffraction data were collected to $3.09 \AA$ resolution (Table 1). The structure was determined by molecular replacement using the apo-KefC structure (PDB entry 3EYW) by removing $\mathrm{NAD}^{+}$as the searching model. The asymmetric unit contains two monomers that form the canonical KTN dimer. In line with the PISA $^{17}$ prediction, gel filtration (Figure $\mathrm{S} 1$ ), size-exclusion chromatography-multiangle laser scattering (SEC-MALS) (Figure S2) analysis, and analytical ultracentrifugation (AUC) (Figure S3) experiments indicated that the two Kef monomers form a stable dimer in solution, at the concentrations used. The core fold of the $S d$ KefQCTD domain is essentially identical to that previously described for the E. coli protein. ${ }^{10,16}$ Each monomer has six $\beta$ strands $(\beta 1-6)$ arranged in a parallel sheet, which is sandwiched between three $\alpha$-helices on one face and one $\alpha$-helix on the other. Two C-terminal helices ( $\alpha 5$ and $\alpha 6)$, resolved in the structure, form a helix-turn-helix-type arrangement and reach across to the other monomer. The penultimate helix $(\alpha 5)$ pairs with a single helix $(\alpha 1)$ from the other monomer and stacks against the $\beta$-sheet from the other subunit. The long C-terminal helix $(\alpha 6)$ makes contacts with both monomers (Figure 2A).

Presence of AMP and Key Interactions in the KTN Domain. Additional unbiased electron density was clearly visible in both nucleotide-binding pockets (Figure 2A), which was best fitted and refined with an AMP molecule. The nucleotidebinding sites are located within the Rossmann fold of each monomer, and the residues that contact AMP come from within one monomer (Figure 2B). However, the phosphate groups are only $12 \AA$ apart and form part of a network of hydrogen bonds that spans the dimer interface where GSH and GSX bind (Figure S4). The side chain of R416 forms salt contacts with the phosphate group of AMP within the same monomer (we arbitrarily define as monomer A) and with E524 from the other monomer (monomer B). E524 (B) in turn makes a further salt bridge with R503 (B). R503 (B) binds to the AMP phosphate group in monomer $\mathrm{B}$. The net result can be considered an octagon with vertices of $\alpha$-phosphate (monomer A), R416 (A), E524 (B), R503 (B), phosphate (B), R416 (B), E524 (A), and R503 (A) (which links to the phosphate of monomer A) (Figure 3). R416 (A) also interacts with the backbone carbonyl oxygen of I505 (B) from the opposite chain. I505 (B) is located at the entrance to the previously identified GSH-binding pocket (Figure S4). The B-factors observed in this region of the X-ray crystal structure are below the mean for the whole protein, indicating the region is well ordered consistent with it being rigid and stable in the crystal form.

The adenosine of the AMP ring sits in a pocket formed by 1478 and $\mathrm{H} 437$ with which it makes $\pi$-stacking interactions. The aniline-like amine (N6) of the purine ring forms a hydrogen bond with D456, and the adjacent pyridine-like nitrogen (N1) atom forms a hydrogen bond with the backbone $\mathrm{NH}$ of $\mathrm{A} 457$ 

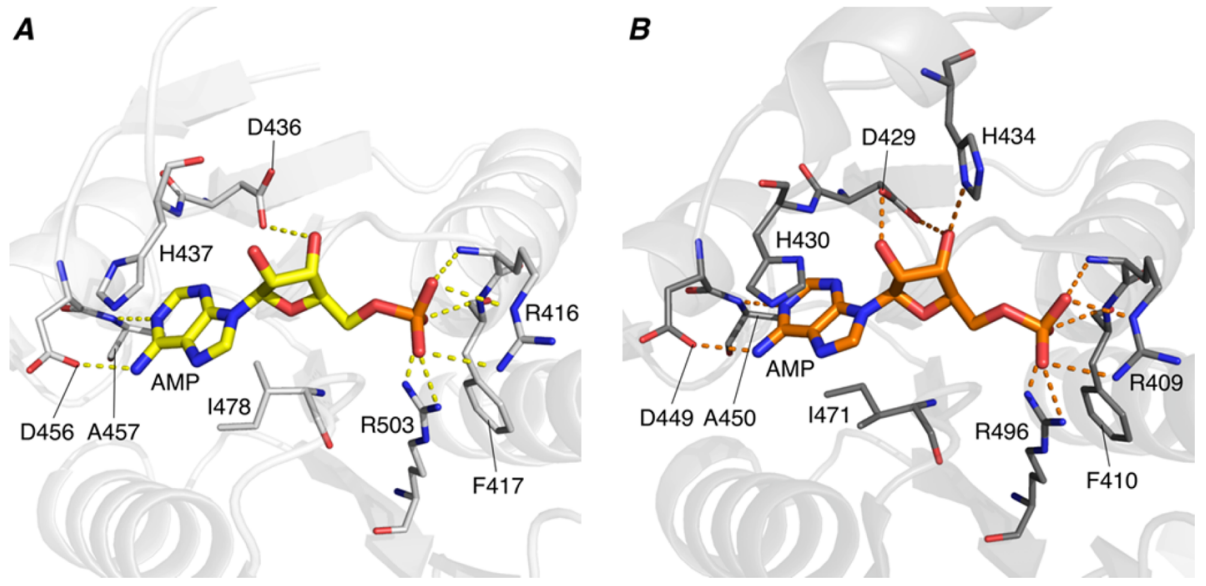

Figure 4. Comparison of the AMP-binding pocket of SdKefQCTD (A, PDB entry 5NC8, AMP carbons colored yellow) and the AMP-binding pocket of the C-terminal domain of EcKefQCTD from E. coli (B, PDB entry 3L9W, AMP carbons colored orange) ${ }^{16}$ The key residues involved in AMP binding are highlighted as lines and are conserved between the two proteins. The equivalent residue of H434 was not well resolved in the SdKefQCTD X-ray crystal structure.

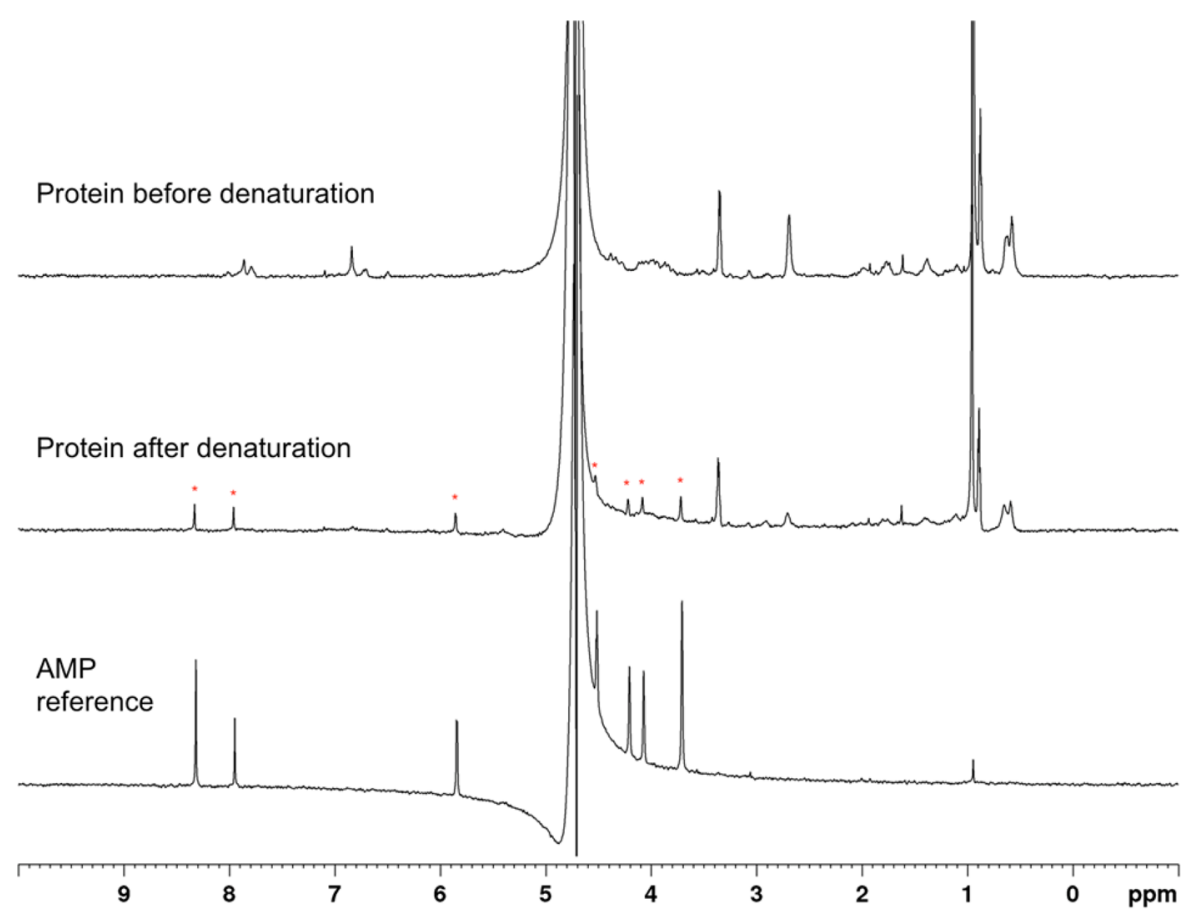

Figure 5. CPMG-edited ${ }^{1} \mathrm{H}$ NMR spectra $(700 \mathrm{MHz}, 278 \mathrm{~K})$ of the native (top) and denatured (middle) SdKefQCTD protein with the reference AMP spectrum (bottom). The red stars denote resonances corresponding to AMP that appear in the SdKefQCTD protein spectrum after denaturation, consistent with the release of AMP from SdKefQCTD following denaturation.

(Figure 4A). This pattern would appear to allow the protein to distinguish between AMP and other nucleotides. $\mathrm{O} 2$ and $\mathrm{O} 3$ of AMP are located close to D436, and $\mathrm{O} 3$ forms a hydrogen bond with this residue. The structure points to a central role for the phosphate group, which forms salt bridges to R416 and R503, and hydrogen bonds to the backbone $\mathrm{NH}$ of R416 and F417. Comparison with the X-ray crystal structure of the CTD of KefC from E. coli, reported by Roosild et al., reveals that the key residues involved in AMP binding are conserved between these two proteins and form similar interactions with AMP (Figure 4B). ${ }^{16}$ An additional interaction between $\mathrm{H} 434$ of E. coli KefC is visible, but the density for this residue is not well resolved in the SdKefQCTD X-ray crystal structure.
Identification of the Bound Nucleotide. Crystallography on its own is not a reliable tool for identifying bound ligands. Consequently, this technique cannot distinguish between AMP and $\mathrm{NAD}^{+}$with a disordered nicotinamide component. Therefore, we performed HPLC analysis to identify the bound nucleotide. Purified SdKefQCTD protein from the batch used for crystallization trials was denatured and supernatant filtered through a $3 \mathrm{kDa}$ cutoff concentrator. The filtrate was analyzed by HPLC, and a peak with a retention time equal to that of an authentic sample of AMP (distinct from ATP and $\mathrm{NAD}^{+}$) was observed (Figure S5A). Further analysis by mass spectrometry shows that the peak has a mass of $348 \mathrm{Da}$, corresponding to protonated AMP (Figure S5A-C). Quantitation by UV extinction coefficient shows an AMP:protein ratio of at least 
0.6 (Figure S5A). Purified full-length integral membrane protein S. denitrificans Kef (expressed in E. coli) was treated in the same way and gave the same result (Figure S5B,C) $(n=2)$.

${ }^{1} \mathrm{H}$ CPMG NMR Analysis. A relaxation-edited ${ }^{1} \mathrm{H}$ NMR experiment was performed on both the native and denatured $S d$ KefQCTD protein using the Carr-Purcell-Meiboom-Gill (CPMG)-based filter. This leads to suppression of the background resonances that are derived from the protein and attenuates those of any ligand bound to the macromolecule. The native protein spectrum showed no resonances corresponding to $\mathrm{AMP}$ (or $\mathrm{NADH}$ or $\mathrm{ADP}$ ), confirming that any nucleotide present was tightly bound to the protein. However, when $S d$ KefQCTD was denatured by being heated for $3 \mathrm{~h}$ at $80^{\circ} \mathrm{C}$, a new set of sharp signals was observed in the spectrum, corresponding to the presence of a free AMP in solution (Figure 5). NADH and ADP were exposed to the same conditions used to denature the protein (heating for $3 \mathrm{~h}$ at $80{ }^{\circ} \mathrm{C}$ ) to formally exclude the possibility that AMP was produced by breakdown of $\mathrm{NADH}$ or $\mathrm{ADP}$. Neither $\mathrm{NADH}$ nor ADP led to AMP production (Figures S7 and S8), nor did the spectra of either compound match those of the molecule detected. AMP was stable to the same heat treatment (Figure S9).

Determining the Stoichiometry of Binding of AMP to the SdKefQCTD Dimer. nESI MS measurements were then performed to accurately determine the stoichiometry of AMP binding under conditions that preserve noncovalent interactions in the gas phase. ${ }^{18}$ The mass spectrum reveals a single charge state series centered around 14+ corresponding to the dimeric protein with two AMP molecules bound (Figure 6A). We did not
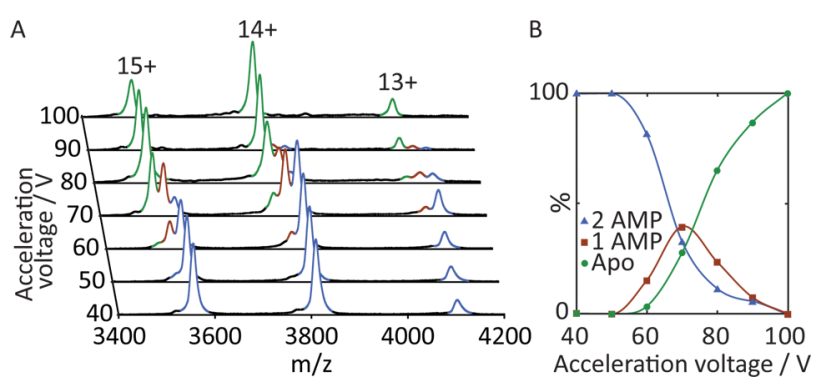

Figure 6. Determination of the stoichiometry of binding of AMP to SdKefQCTD through native mass spectrometry. (A) Mass spectra of $S d$ KefQCTD reveal the sequential removal of two AMP molecules with an increasing level of collisional activation. (B) Proportion of bound $S d K e f Q C T D$, as a function of collision voltage, averaged across all charge states.

detect apoprotein or a dimer with one AMP molecule bound, indicating the protein is homogeneously and fully "loaded" with AMP. Activation, achieved by accelerating the protein into a collision cell, ${ }^{18}$ results in peaks corresponding to the mass of a protein dimer with a single AMP molecule bound, and an apo dimer (Figure 6 and Table S2). This is consistent with the sequential loss of neutral AMP.

AMP Stabilizes SdKefQCTD. Given the regulatory roles played by ATP (and NADH) in TrkAH and KtrAB, we sought to investigate the influence of different nucleotides on the stability of SdKefQCTD in the presence and absence of the peptide ligands GSH and ESG. We used DSF, ${ }^{19}$ in which the protein is heated in the presence of a fluorescent dye (SYPRO orange), and as the protein unfolds, an increase in fluorescence is observed. The point at which the gradient of the fluorescence increase is greatest is the measured melting temperature of the protein
$\left(T_{\mathrm{m}}\right)$. Repeating the experiment in the presence of a ligand that binds to, and hence stabilizes, a folded state of the protein results in an increase in $T_{\mathrm{m}}$. The change in melting temperature between the free and ligand-bound protein states $\left(\Delta T_{\mathrm{m}}\right)$ roughly correlates to the ligand's affinity for the protein; however, there are some caveats. In particular, larger $\Delta T_{\mathrm{m}}$ values are typically observed for more entropically driven (e.g., hydrophobic) binding. Therefore, it can be difficult to directly compare $\Delta T_{\mathrm{m}}$ values for compounds with very different physicochemical properties. $^{20}$

We hypothesized that stabilization of the $\operatorname{Kef} T_{m}$ by AMP would occur despite the protein being purified with a high percentage of the nucleotide-binding sites occupied by AMP. We assumed that as the temperature increases, and the protein unfolds, the off rate of AMP would also increase, allowing the stabilizing effect of AMP binding to be observed. However, in the presence of the exogenous AMP, the equilibrium would be shifted, partially compensating for the increased off rate, resulting in protein stabilization.

Conducting the DSF experiment in the presence of AMP resulted in a $\Delta T_{\mathrm{m}}$ of $+15^{\circ} \mathrm{C}$ (Figure $7 \mathrm{~A}$ ), which is consistent with tight binding of AMP to $S d$ KefQCTD. ADP showed a $\Delta T_{\mathrm{m}}$ of +7 ${ }^{\circ} \mathrm{C}$; ATP and adenosine had no effect on $T_{\mathrm{m}}$ (Figure $7 \mathrm{~A}$ ), suggesting that much of AMP's affinity for SdKefQCTD derives from the binding of the phosphate group (Figure 7A). This observation is consistent with the phosphate group-protein interactions that were observed in the SdKefQCTD X-ray crystal structure (Figure 4A) and our computational studies (see below). NADH showed a $\Delta T_{\mathrm{m}}$ of $+3{ }^{\circ} \mathrm{C}$, but NADP and $\mathrm{NAD}^{+}$ had little effect on $T_{\mathrm{m}}$.

To compare the binding of the peptide and nucleotide ligands, and to determine whether their binding was competitive, DSF experiments in the presence of two ligands were conducted (Figure 7B and Figure S10). It has previously been shown that GSH has little effect on $T_{\mathrm{m}}$, which is consistent with its low affinity for SdKefQCTD. ${ }^{12}$ ESG, which has a higher affinity for $S d$ KefQCTD, has a $\Delta T_{\mathrm{m}}$ of $+7{ }^{\circ} \mathrm{C}$. ESG binding was additive with the other ligands (Figure S10); for example, the addition of AMP and ESG gives a $\Delta T_{\mathrm{m}}$ of $+18^{\circ} \mathrm{C}$. No release of AMP was observed upon binding of the high-affinity ESG analogue, tertbutyl-S-glutathione (Figure S11), using CPMG NMR. These data are consistent with structural data showing distinct nucleotide- and peptide-binding sites.

Mutagenesis Studies for Probing the Role of AMP When It Is Bound to the Rossmann Fold of SdKef and SdKefQCTD. Mutation of three residues, R416, D436, and H437, was performed in both SdKefQCTD and the full-length protein to test our hypothesis that AMP binding was important for protein stability and, thus, function. We selected H437 because it forms the top of the AMP-binding pocket and stacks with the purine ring (Figure 8). D436 was identified to form hydrogen bonds with the two hydroxyl groups on the ribose ring of AMP (Figure 8) and R416 because it directly contacts the AMP phosphate group (Figure 8). Our computational studies (see below) predicted this to be a key interaction, and in general, interactions between an arginine residue and a phosphate group are typically strong ${ }^{21}$ and would be expected to contribute significantly to the binding interaction of Kef with AMP. The SdKefQCTD mutants were expressed in E. coli strain MJF335, which lacks the chromosomally encoded KefC and KefB proteins and does not exhibit endogenous GSH biosynthesis because of the disruption of the gshA locus. This strain permits the presence of GSH to be controlled by medium supplementation. Whole 
A

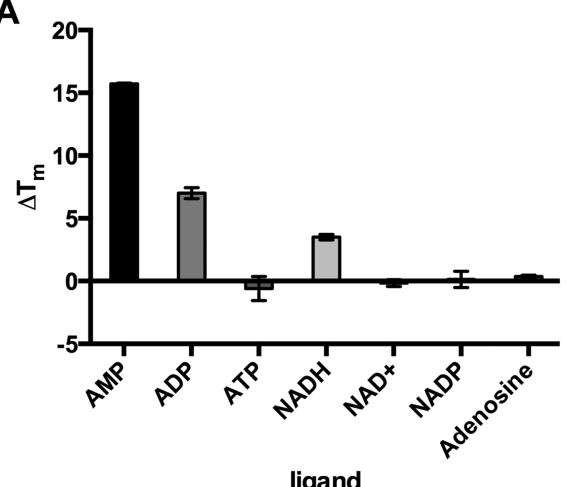

B

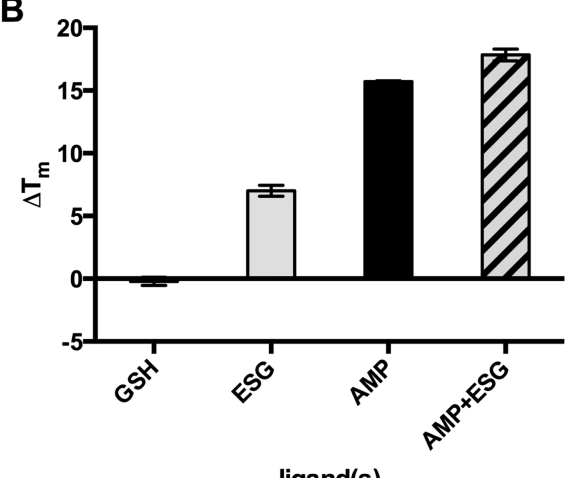

Figure 7. (A) DSF experiments to determine the effect of nucleotides on the stabilization of SdKefQCTD. It is shown that AMP is most effective at stabilizing $S d$ KefQCTD with a $\Delta T_{\mathrm{m}}$ of $+15^{\circ} \mathrm{C}$. (B) DSF experiments to determine the effect of both AMP and ESG on the stabilization of $S d$ KefQCTD. Little stabilization is provided by GSH, whereas ESG shows a $\Delta T_{\mathrm{m}}$ of $+7^{\circ} \mathrm{C}$. The stabilization in the presence of both AMP and ESG is $+18^{\circ} \mathrm{C}$, which is consistent with separate binding sites for these two ligands.

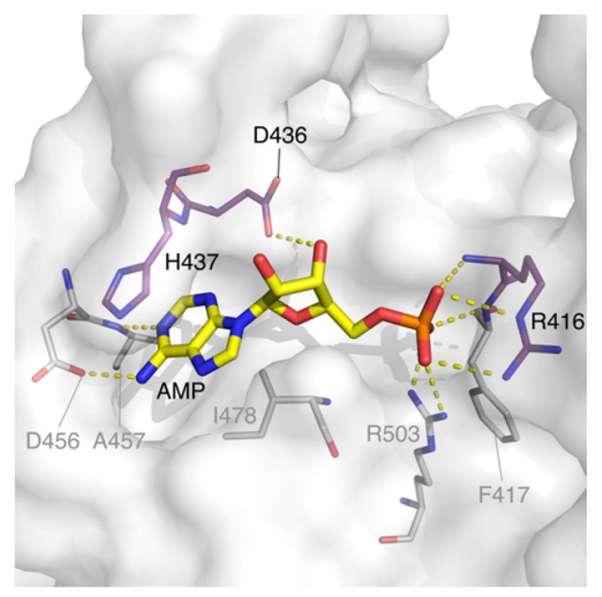

Figure 8. AMP-binding residues that have been investigated by mutagenesis studies are highlighted with purple carbons. AMP is shown as a stick representation (yellow carbons). Image generated using PyMOL and the X-ray crystal structure of SdKefQCTD (PDB entry $5 \mathrm{NC} 8$ ).

cell-based $\mathrm{K}^{+}$efflux assays were performed with the full-length mutant proteins expressed in MJF335 ( $\mathrm{KefB}^{-}, \mathrm{KefC}^{-}, \mathrm{Gsh}^{-}$) supplemented during growth with $1 \mathrm{mM} \mathrm{GSH}$ (Table S3).

H437. H437 forms the top of the AMP-binding pocket and is observed to be in the proximity $(\sim 3.5 \AA)$ of the purine ring of AMP (Figure 8). It is, therefore, plausible that stacking interactions between the two aromatic rings stabilize this interaction. The H437A and M437N mutations remove the stacking interactions and give an indication of how important this residue is to the affinity of $S d$ Kef for AMP. These mutations, in either $S d$ KefCTD or $S d$ Kef, had only limited effects on protein expression and function. Both $\mathrm{H} 437 \mathrm{~A}$ and $\mathrm{H} 437 \mathrm{~N}$ showed expression levels similar to that of the wild-type protein in $S d \mathrm{Kef}$ (Figure 9A) and SdKefQCTD (Figure 9B). Consistent with the expression data, full-length proteins carrying either $\mathrm{H} 437 \mathrm{~A}$ or $\mathrm{H} 437 \mathrm{~N}$ were active in a $\mathrm{K}^{+}$efflux assay, although both proteins displayed altered kinetics; $\mathrm{H} 437 \mathrm{~N}$ exhibited close to wild-type activity in its initial $\mathrm{K}^{+}$loss rate, but the final extent was reduced. On the other hand, H437A displayed $~ 50 \%$ of wild-type activity in the initial rate of $\mathrm{K}^{+}$lost, but the overall loss was similar to that of the wild type. Taken together, these results indicate that the purine ring of AMP contributes only modestly to its affinity for SdKef.

D436. D436 forms hydrogen bonds with the two hydroxyl groups on the ribose ring of AMP (Figure 8). D436E would be expected to form similar interactions with AMP. Consistent with this hypothesis, the D436E mutant in both $S d$ Kef and $S d$ KefQCTD exhibited approximately wild-type expression levels (Table 2 and Figure 9). The NEM-elicited efflux of $\mathrm{K}^{+}$ from the $S d$ Kef D436E mutant was not substantially altered from that of the wild-type protein. The uncharged D436N would be expected to form weakened hydrogen bonding interactions with AMP, while D436A would be unable to form hydrogen bonds with AMP. Both D436A and D436N displayed severely reduced levels of protein expression in both SdKef and SdKefQCTD

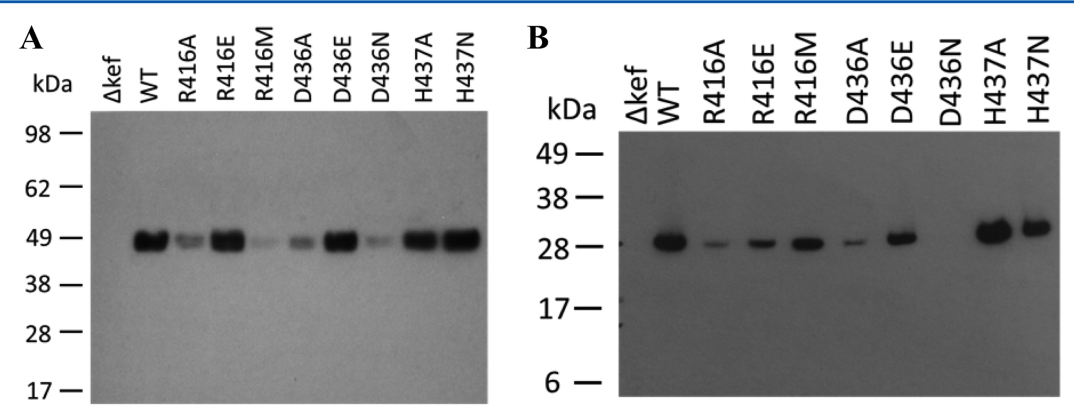

Figure 9. Western blot of the (A) full-length $S d$ Kef and (B) truncated $S d K e f Q C T D$ mutants. The wild type (WT) and the mutants in each plasmid were expressed in MJF373 cells and overproduced by induction with $0.3 \mathrm{mM} \mathrm{IPTG}$. (A) Membrane fractions or (B) soluble fractions were isolated; $15 \mu \mathrm{g}$ of protein per well was separated via SDS-PAGE and transferred to a nitrocellulose membrane, and an antibody against the C-terminal His ${ }_{6}$ tag was used for detection of the proteins. MJF373 alone was used as a control ( $\Delta$ kef). 
Table 2. Protein Yields and Percentages of AMP Retention of the D436E and D436A Mutants

$\begin{array}{ccl}\text { S. denitrificans Kef mutant } & \text { protein yield }(\mathrm{mg} / \mathrm{L}) & \text { AMP retention (\%) } \\ \text { WT-FL } & 3 \pm 1 & 107.3 \pm 21.5(n=2) \\ \text { WT-QCTD } & 9 \pm 1 & 101.5 \pm 11.6(n=2) \\ \text { D436E-QCTD } & 8 \pm 2 & 99.7 \pm 23.2(n=2) \\ \text { D436A-QCTD } & 2 \pm 1 & 14.7 \pm \mathrm{n} / \mathrm{a}(n=1)\end{array}$

(Table 2); for SdKefQCTD D436N, no protein was detected (Figure 9B). A significant decrease in the $\mathrm{K}^{+}$activity of the $S d \mathrm{Kef}$ $\mathrm{D} 436 \mathrm{~A}$ and $\mathrm{D} 436 \mathrm{~N}$ proteins was found, in line with the reduced level of expression of these two mutant proteins (Figure 9A). A low level of expression could indicate lower protein stability resulting from impaired AMP binding.

R416. The R416A, R416M, and R416E mutations would be expected to abolish phosphate binding. R416A shows low expression levels for both the full-length [SdKef (Figure 9A)] and truncated $[S d$ KefQCTD (Figure $9 \mathrm{~B})]$ proteins. R416M also showed low expression levels for $S d \mathrm{Kef}$ and a reduced level of expression for SdKefQCTD. These results are consistent with the mutations decreasing the level of binding of AMP to the KTN domain. However, while R416E showed a very low level of expression for SdKefQCTD (Figure 9B and Figure S12), the mutated full-length $S d$ Kef protein showed wild-type expression levels (Figure 9A). This observation implies that this mutant is more stable in the full-length protein. While R416A retained some activity in the $\mathrm{K}^{+}$assay, $\mathrm{R} 416 \mathrm{M}$ had substantially reduced activity, and an $\mathrm{R} 416 \mathrm{E}$ mutant was completely inactive, consistent with the proposed hypothesis. While AMP might still be accommodated in R416A, steric occlusion of the binding site would be expected from R416M. R416E would likely be the most disruptive to AMP binding, as the negatively charged $\gamma$ carboxylate of glutamate would repel the phosphate group of
AMP. However, it is possible that protein folding is better in the full-length protein than in the truncated construct. Once folded, it is possible that E416 forms a salt bridge with R503, stabilizing the protein while not binding AMP, explaining the stable but inactive protein.

HPLC Analysis of AMP Retention by the Mutated Proteins. To determine whether the variation in protein stability and function correlated to the degree of AMP binding, we used HPLC analysis to assess the amount of AMP that was co-purified with the mutated proteins (Figures 10 and 11). AMP retention by purified SdKefQCTD D436E and D436A proteins was analyzed as described above, and it was observed that the $\mathrm{D} 436 \mathrm{E}$ protein retained almost the same levels of AMP as the wild type whereas the D436A protein had only $20 \%$ of the normal level (Figure 10). When AMP retention by R416E was analyzed by HPLC, very little AMP could be detected (Figure 11).

Computational Analysis of the Effect of Ligand Binding on SdKefQCTD Stability. To investigate computationally the effect of AMP and related ligands on protein stability, molecular dynamics (MD) simulations were performed. To include regions of the protein that are disordered in the X-ray crystal structure, the SdKefQCTD homology model previously reported by Healy et al. ${ }^{12}$ was employed. Four systems were evaluated: (a) SdKefQCTD bound to one GSH molecule and two AMP molecules (one bound to each of the Rossmann folds in the dimer), (b) SdKefQCTD bound to one ESG molecule and two AMP molecules, (c) SdKefQCTD bound to one GSH molecule, and (d) SdKefQCTD bound to one ESG molecule.

Consistent with the experimental data described above, $\mathrm{MD}$ simulations of the systems with AMP bound to the Rossmann fold were more stable than the same model without AMP [as quantified by smaller per-residue fluctuations (shown in Figure 12A,B)]. The SdKefQCTD-AMP-GSH complex did not show

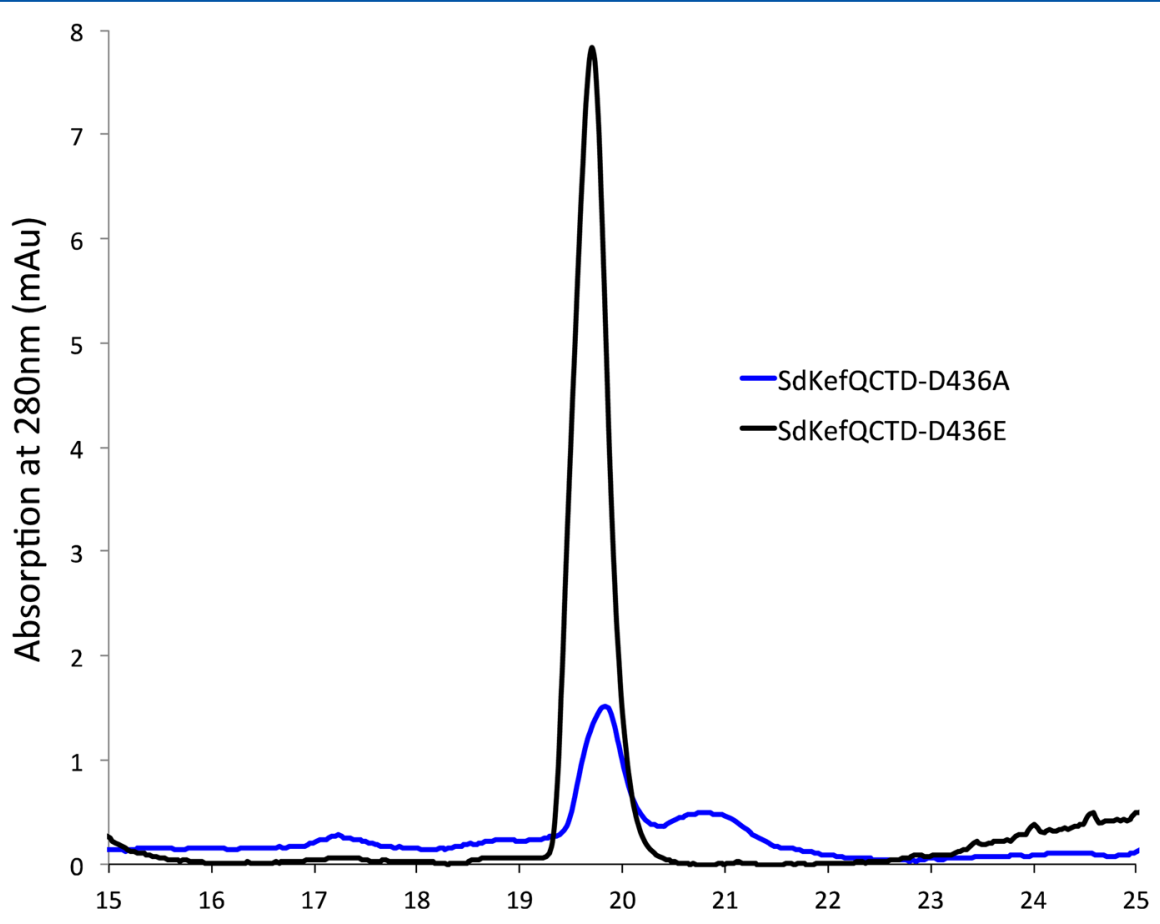

Figure 10. AMP percentage of retention calculated by comparing the absorption at $280 \mathrm{~nm}\left(A_{280}\right)$ of the denatured proteins and AMP standards that were run the same day, at equal concentrations, at equal sample volumes, and in identical buffers. A representative example is shown. Mutants D436A and D436E were studied; $100 \mu \mathrm{L}$ of a $200 \mu \mathrm{M}$ sample was treated as described in Materials and Methods, and all resulting single peaks appearing in the gel filtration profiles were subjected to further mass spectrometry analysis for nucleotide identification (Figure S5D-F). 
A

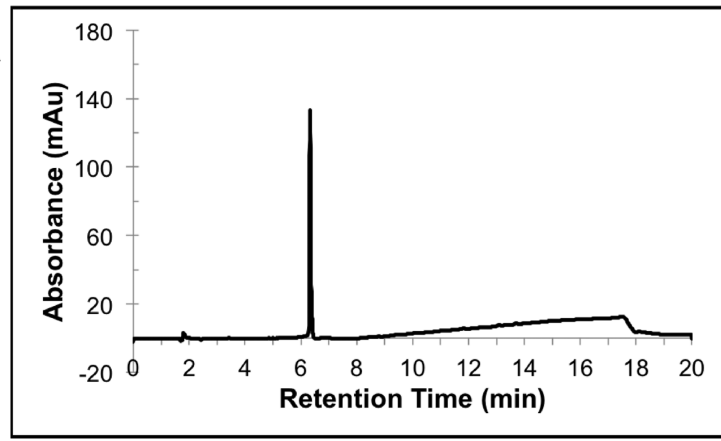

B

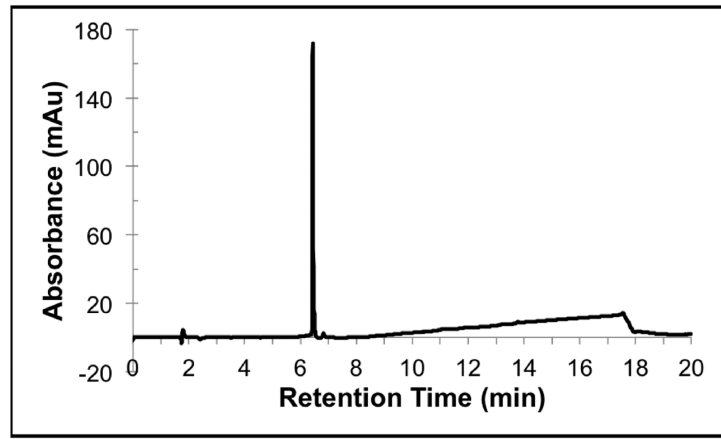

C

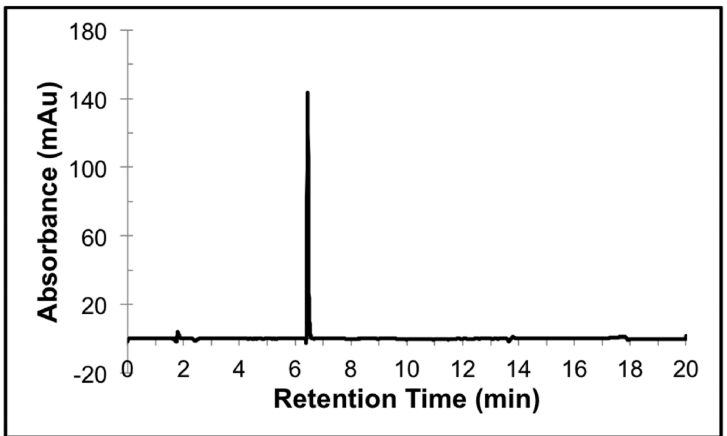

E

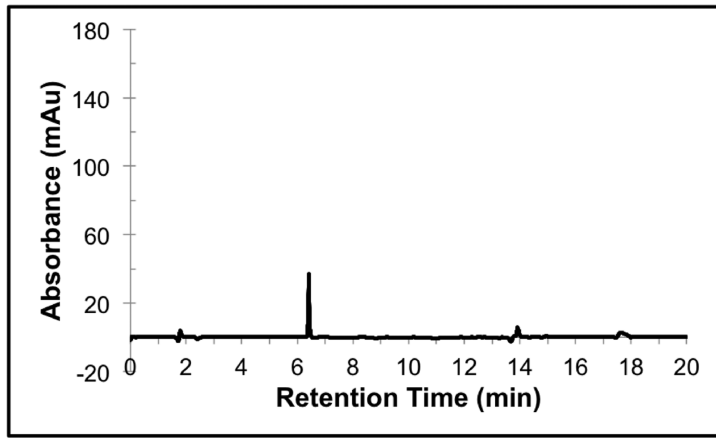

F

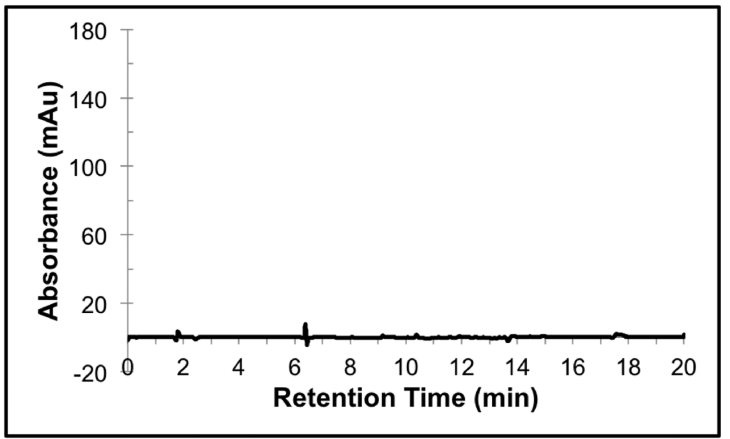

G

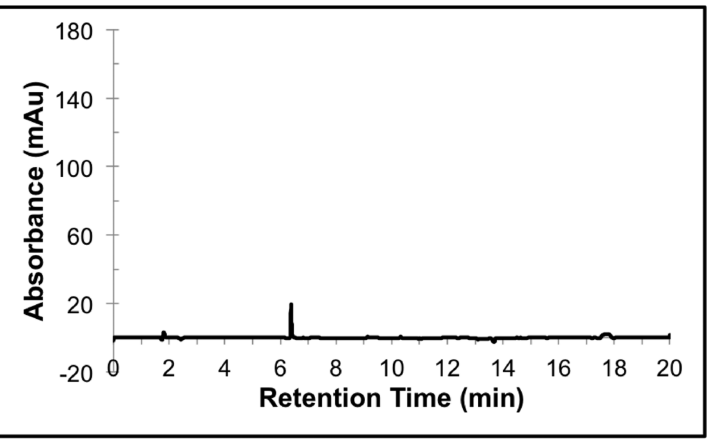

D

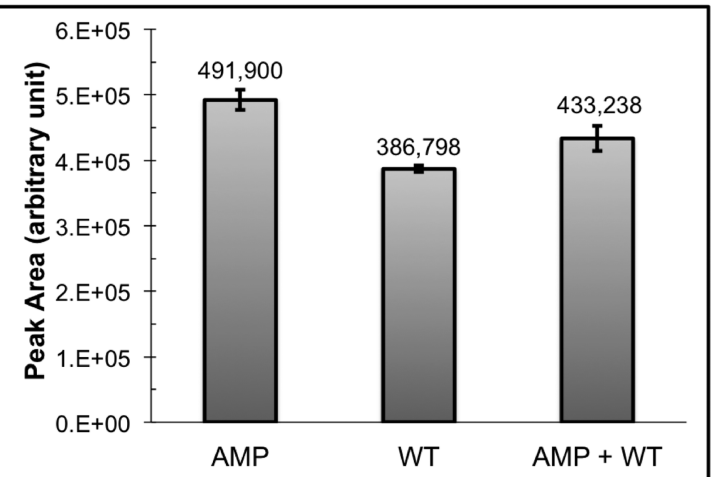

H

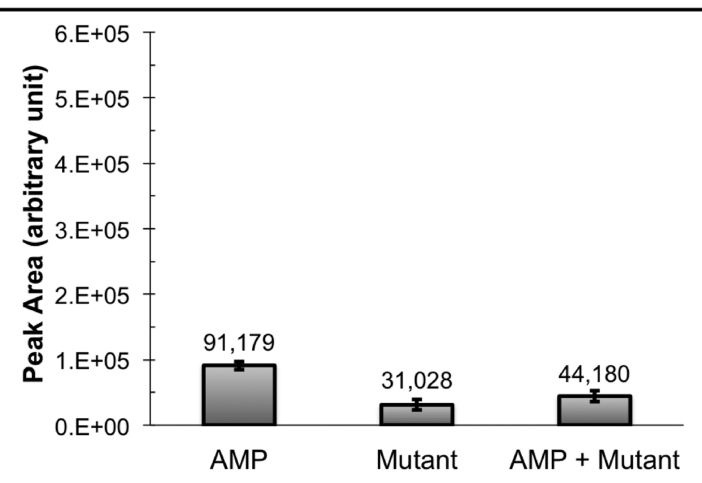

Figure 11. HPLC analysis of AMP released from heat-denatured $S d$ KefQCTD and $S d$ KefQCTD(R416E). All experiments were conducted under the same HPLC conditions (see Materials and Methods for details). (A) HPLC profile of $50 \mu \mathrm{M}$ pure adenosine monophosphate (AMP). (B) HPLC profile of $50 \mu \mathrm{M}$ denatured wild-type protein (WT) - SdKefQCTD. (C) Spiking experiment containing equal concentrations $(25 \mu \mathrm{M}$ each) of pure AMP and denatured WT (i.e., AMP + WT). (D) Quantification of HPLC peak areas of panels A-C. Data shown are mean \pm standard deviation (SD) values from three different experiments $(n=3)$. (E) HPLC profile of $8.6 \mu \mathrm{M}$ pure AMP. (F) HPLC profile of $8.6 \mu \mathrm{M}$ denatured mutant protein (Mutant) $S d \operatorname{KefQCTD}(\mathrm{R} 416 \mathrm{E})$. (G) Spiking experiment containing equal concentrations (4.3 $\mu \mathrm{M}$ each) of pure AMP and the denatured mutant (i.e., AMP + Mutant). (H) Quantification of HPLC peak areas of panels E-G. Data shown are mean \pm SD values from three different experiments $(n=3)$.

large conformational changes during the entire simulation. This model had a stabilized root-mean-square deviation (RMSD), relative to the initial point of the $\mathrm{MD}$, of approximately $2.2 \AA$ after the first $5 \mathrm{~ns}$ of MD (Figure 12C); the SdKefQCTD-AMPESG complex stabilized after $25 \mathrm{~ns}$ of $\mathrm{MD}$ at an approximately
2.3 Å RMSD (Figure 12C). This behavior is predictable, because the initial homology model was based on the EcKefQCTD X-ray crystal structure with AMP and GSH both bound (PDB entry 3L9W), so some conformational changes are to be expected upon substitution of GSH with ESG. In contrast, a 40 ns 

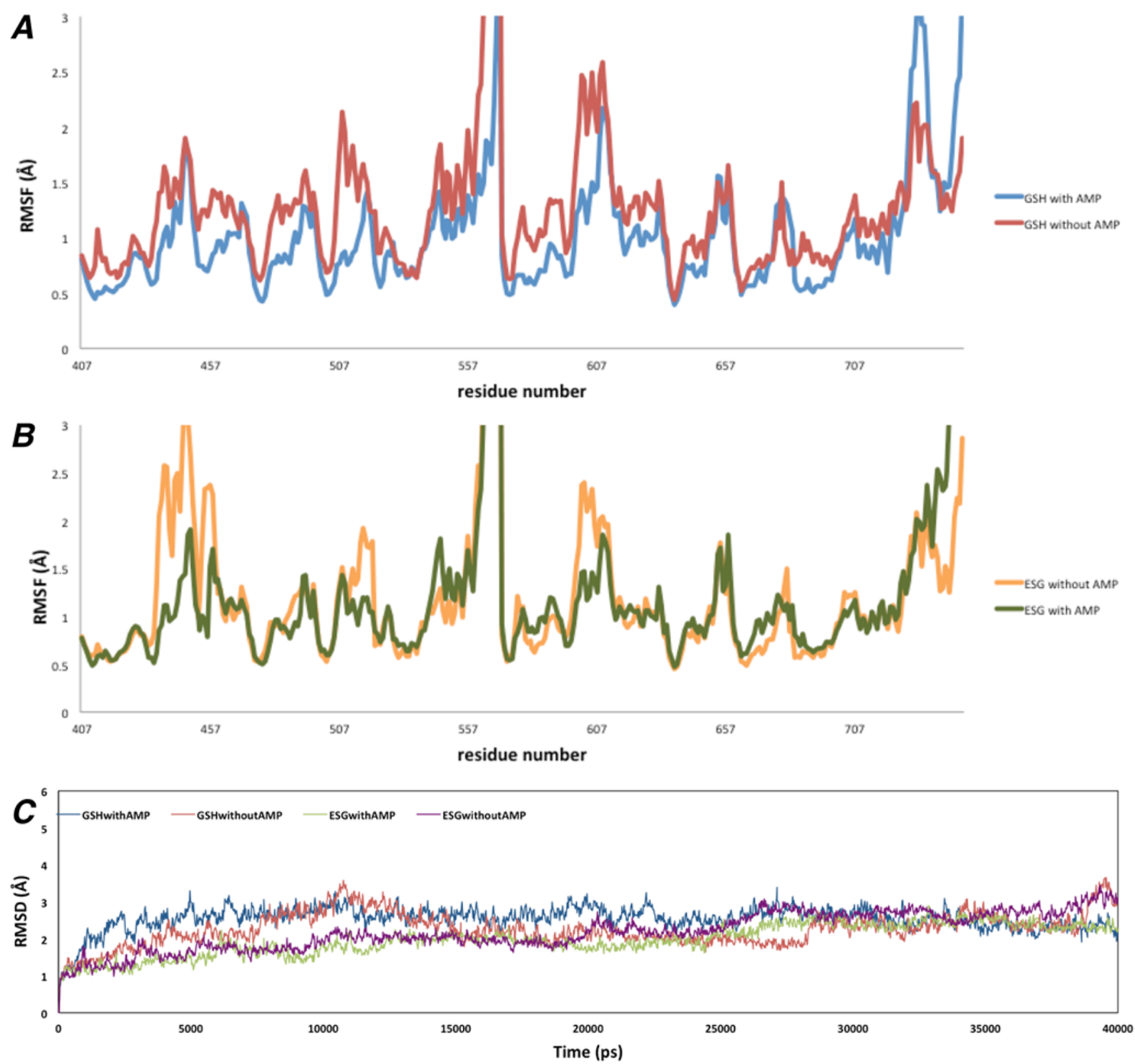

Figure 12. (A) Per-residue root-mean-square fluctuations (RMSF) of the $\mathrm{C} \alpha$ atoms of a homology model of SdKefQCTD in the presence of either GSH and AMP (blue) or only GSH (red). (B) Per-residue RMSF of the C $\alpha$ atoms of a homology model of SdKefQCTD in the presence of either ESG and AMP (green) or only GSH (yellow). (C) Temporal root-mean-square deviation (relative to the starting structure) for C $\alpha$ atoms during a $40 \mathrm{~ns}$ MD simulation for SdKefQCTD in complex with GSH (red), GSH and AMP (blue), ESG (purple), or ESG and AMP (green).

simulation time was insufficient to observe stability for SdKefQCTD-GSH and SdKefQCTD-ESG complexes without AMP bound, which displayed larger geometric fluctuations, as judged by RMSD values of $>3 \AA$. These results are qualitatively consistent with AMP being an important factor in stabilizing the SdKefQCTD structure.

The AMP-R416 interactions (electrostatic and hydrogen bonding) were maintained for $40 \mathrm{~ns}$ of $\mathrm{MD}$, with one or two hydrogen bonds observed throughout the simulation (see Figure S13 for further information). Hydrogen bonding interactions at the interface of the protein dimer (R416, E524, R503, and I505) may help to provide structural rigidity. A 40 ns simulation of SdKefQCTD bound only to ESG (Figure 12B) shows the high flexibility of the region containing Pro439-Leu445 residues, as a result of unfavorable steric interactions with the succinimide ring of ESG. This effect is not observed in the SdKefQCTD-AMPESG complex, because of hydrogen bonds with Asp436 (Figure S14 and Figure 12B) and aromatic face-to-face (so-called $\pi$ stacking) interactions with His437 (Figure S15). These interactions are maintained during $40 \mathrm{~ns}$ of $\mathrm{MD}$ simulation and increase the structural stability of the amino acids in the P439L445 region.

\section{DISCUSSION}

A combination of crystallography, DSF, HPLC analysis, MS, and NMR studies provides evidence that the SdKefQCTD domain binds AMP; HPLC analysis suggests the full-length protein also binds AMP. The stoichiometry of the complex, determined using MS and HPLC, is 1:1 (one AMP molecule per SdKefQCTD monomer), which is consistent with that observed by 
crystallography. Although we were unable to measure a direct binding constant, several pieces of evidence point to this being a high-affinity interaction, which we suggest is approximately in the nanomolar range. First, it was possible to remove AMP only by denaturing the protein and, second, the high degree of thermal stabilization of $S d$ KefQCTD by adding additional AMP; third, we were not able to exchange AMP with related nucleotides, and finally, the AMP must have been bound in the cytoplasm of $E$. coli, where the concentration of AMP is much lower than those of other adenosine-containing nucleotides. The estimated cellular concentrations of relevant nucleotides in E. coli are $9 \mathrm{mM}$ ATP, $0.5 \mathrm{mM}$ ADP, $0.28 \mathrm{mM}$ AMP, $2.6 \mathrm{mM} \mathrm{NAD}^{+}$, and $0.08 \mathrm{mM}$ $\mathrm{NADH} .{ }^{22}$ AMP pools are integrated with those of ADP and ATP via the activity of adenylate kinase. The $E$. coli adenylate kinase has a high affinity for AMP $(\sim 30 \mu \mathrm{M})$ and a high $V_{\max }[1247$

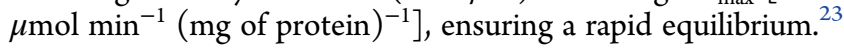
Thus, the growing cell maintains an ATP:ADP:AMP ratio of 100:10:2 (stationary phase cells generally have higher AMP concentrations). We did not detect any protein with $\mathrm{NAD}^{+}$, $\mathrm{NADH}$, or ATP bound, which implies that in the cell the domain has a binding constant for AMP at least 200-fold tighter than that for $\mathrm{NAD}^{+}$, 6-fold tighter than that for $\mathrm{NADH}, 700$-fold tighter than that for ATP, and 35-fold tighter than that for ADP (these values are predicated upon an estimated upper limit of $5 \%$ for missed detection of such complexes). The observation that the protein appears (within the error of our measurement) to be fully occupied with AMP despite extensive purification suggests a very tight binding. It should be noted, however, that the observed $K_{\mathrm{d}}$ value of the KtrAB system for nucleotides falls well below the concentration of cellular pools, ${ }^{24}$ and it has been speculated that the change in these pools is accompanied by nucleotide exchanges that are intrinsic to the allosteric transition.

The Kef system is normally in an inactive, GSH-bound, state. When GSH is replaced by an electrophilic adduct of GSH, this triggers channel opening. The formation of such an adduct occurs when the bacterial cell is intoxicated, and the activation of the $\mathrm{K}^{+}$efflux system is part of the survival response. In such a scheme, what is the role of AMP? Dimeric Kef protein possesses two GSH-binding sites that are located at the interface between the two protein monomers. These sites are in the proximity of the two nucleotide-binding sites, and in fact, complex series of hydrogen bond and salt bridge interactions link AMP, the dimer, and the residues that form the GSH-binding site (Figure 3). We hypothesized that the GSH (and GSH adduct)-binding site requires dimer formation, which in turn is dependent on the presence of AMP. Thus, we propose AMP plays a vital role in creating a protein architecture that can respond to the chemical change induced by binding GSH adducts. Specifically, AMP makes a number of contacts with helix 418-437 that extends across the dimer interface and is thought to be involved in the conformational change associated with Kef channel gating.

In support of this model, we note that addition of exogenous AMP results in significant stabilization of the protein, which is much larger than typically expected for stabilization of a monomeric protein alone. As SdKefQCTD always co-purifies with the bound nucleotide, we were unable to generate a true apo structure to measure the stabilizing effect of ESG on its own; however, we noted its stabilization effect was additive to AMP, and NMR analysis confirmed that ESG binding did not displace AMP. Computational modeling was used to generate a structure lacking bound AMP, and classical MD simulations showed lower structural stabilities, even when GSH was added. By contrast, models with AMP remained stable regardless of whether GSH was present. Experimental confirmation of the importance of AMP binding for structural integrity was obtained by a panel of mutants selected to disrupt AMP binding. In each case, the mutants displayed a decrease in the AMP content of purified protein, reduced stability, and loss of activity.

Previous crystallographic studies of KTN domains from channels and transporters have identified a variety of bound nucleotides. Usually, these have been ligands added during crystallization rather than being carried through during purification, and in many cases, the apoprotein is readily isolated. For the octameric assemblies, the crystallographic evidence of the role of these specific nucleotides has been supported by biochemical evidence. In contrast, for the determined structures of the dimeric complexes, the observed density is consistent with AMP, but crystallography on its own is not a definitive tool for the identification of ligands. For the E. coli KefC KTN domain structures, density consistent with AMP was observed in two crystal forms (the apoprotein and the GSH-bound form), whereas a sulfate ion was found in the AMP-binding site in the ESG-bound form. These structures have provided valuable insight into the nature of the conformational change induced by the electrophilic modification of GSH. A KTN domain structure with AMP has been deposited by a structural genomics consortium (PDB entry 3C85), but no comment about what if any ligands were added and the basis of ligand identification is available. Thus, it seems plausible that the dimeric KTN modules have AMP as a structural moiety, while the octameric proteins have the nucleotides, most probably ATP and $\mathrm{NADH}$, as allosteric modulators of channel activity.

A further difference between the dimeric and octameric assemblies is the recognition of additional ligands, such as GSH, that regulate the activity of the dimeric systems, unlike in the octamers where dissociation of the nucleotide is used to achieve activation. In contrast to the other KTN domains (i.e., Trk, Ktr, and potentially the channels) for which the nucleotide may play a major role in gating, we propose AMP in Kef is required to form the structure that binds GSH and its adducts. It follows, therefore, that the affinity for the gating ligands (whether nucleotide or GSH) should be within the dynamic range of actively metabolizing cells. While a stabilizing ligand should bind sufficiently tightly to ensure the integrity of the protein under all metabolic states.

\section{ASSOCIATED CONTENT}

\section{S Supporting Information}

The Supporting Information is available free of charge on the ACS Publications website at DOI: 10.1021/acs.biochem. $7 \mathrm{~b} 00300$.

E. coli strains and plasmids used in the study, evidence of $S d$ KefQCTD dimer formation in solution, a comparison of the GSH/GSX-binding site of EcQCTD and the presumed GSH/GSX-binding site of SdKefQCTD, additional evidence of binding of AMP to $S d$ Kef and $S d$ KefQCTD, and additional computational figures (PDF)

\section{AUTHOR INFORMATION}

\section{Corresponding Authors}

*E-mail: stuart.conway@chem.ox.ac.uk. Phone: +44(0)1865 285109.

*E-mail: naismith@strubi.ox.ac.uk. Phone: +44(0)1235 567701.

*E-mail: i.r.booth@abdn.ac.uk. Phone: +44(0)1224 437396. 


\section{ORCID}

Robert S. Paton: 0000-0002-0104-4166

Timothy D. W. Claridge: 0000-0001-5583-6460

James H. Naismith: 0000-0001-6744-5061

Stuart J. Conway: 0000-0002-5148-117X

\section{Present Address}

-J.H.: Department of Pharmaceutical and Biological Chemistry, UCL School of Pharmacy, University College London, 29/39 Brunswick Square, London WC1N 1AX, U.K.

\section{Author Contributions}

C.P., S.C.G., S.E., and A.K.N.C. contributed equally to this work.

\section{Funding}

The project is supported by the Wellcome Trust (WT092552MA and WT100209MA to I.R.B., J.H.N., S.M., and S.J.C.), a Biotechnology and Biological Sciences Research Council (BBSRC) grant (BB/H017917/1), and a European Union Marie Curie ITN Award (NICHE; 289384) that supported S.E. C.P. also acknowledges additional support by a Tenovus Scotland grant award (T15/41). W.A.C. is supported by a Science Without Borders scholarship. The authors acknowledge that the work presented here made use of the Emerald High Performance Computing facility made available by the Centre for Innovation, formed by the universities of Oxford, Southampton, Bristol, and University College London in partnership with the STFC Rutherford-Appleton Laboratory. R.S.P. acknowledges the use of the EPSRC UK National Service for Computational Chemistry Software (NSCCS) at Imperial College London in performing this work (CHEM773). R.S.P. is grateful to NVIDIA for the generous donation of Tesla GPUs as part of the academic partnership scheme. S.J.C. and A.K.N.C. thank the European Commission for the award of a Marie Curie Fellowship to A.K.N.C. (660156, FLUOROKEF). S.J.C. and S.C.G. thank the EPSRC for studentship support for S.C.G. S.J.C. thanks St. Hugh's College, Oxford, for research support. S.A.C. and J.L.P.B. are grateful to BBSRC and Waters Corp for an Industrial CASE studentship (BB/L017067/1).

Notes

The authors declare no competing financial interest.

\section{ACKNOWLEDGMENTS}

We thank Dr. Magnus Alphey for help with crystal mounting and Dr. Sally Shirran for mass spectrometry data analysis and technical assistance.

\section{REFERENCES}

(1) Jiang, Y., Pico, A., Cadene, M., Chait, B. T., and MacKinnon, R. (2001) Structure of the RCK Domain from the E. coli K+ Channel and Demonstration of Its Presence in the Human BK Channel. Neuron 29, 593-601.

(2) Follmann, M., Becker, M., Ochrombel, I., Ott, V., Krämer, R., and Marin, K. (2009) Potassium transport in corynebacterium glutamicum is facilitated by the putative channel protein $\mathrm{CglK}$, which is essential for $\mathrm{pH}$ homeostasis and growth at acidic pH. J. Bacteriol. 191, 2944-2952.

(3) Adams, M. J., Ford, G. C., Koekoek, R., Lentz, P. J., McPherson, A., Rossmann, M. G., Smiley, I. E., Schevitz, R. W., and Wonacott, A. J. (1970) Structure of Lactate Dehydrogenase at $2.8 \AA ̊$ Resolution. Nature 227, 1098-1103.

(4) Loi, V. V., Rossius, M., and Antelmann, H. (2015) Redox regulation by reversible protein S-thiolation in bacteria. Front. Microbiol. 6, 187.

(5) Newton, G. L., Rawat, M., La Clair, J. J., Jothivasan, V. K., Budiarto, T., Hamilton, C. J., Claiborne, A., Helmann, J. D., and Fahey, R. C. (2009) Bacillithiol is an antioxidant thiol produced in Bacilli. Nat. Chem. Biol. 5, 625-627.
(6) Gaballa, A., Newton, G. L., Antelmann, H., Parsonage, D., Upton, H., Rawat, M., Claiborne, A., Fahey, R. C., and Helmann, J. D. (2010) Biosynthesis and functions of bacillithiol, a major low-molecular-weight thiol in Bacilli. Proc. Natl. Acad. Sci. U. S. A. 107, 6482-6486.

(7) Helmann, J. D. (2011) Bacillithiol, a new player in bacterial redox homeostasis. Antioxid. Redox Signaling 15, 123-133.

(8) Ferguson, G. P., Munro, A. W., Douglas, R. M., McLaggan, D., and Booth, I. R. (1993) Activation of potassium channels during metabolite detoxification in Escherichia coli. Mol. Microbiol. 9, 1297-1303.

(9) Ferguson, G. P., McLaggan, D., and Booth, I. R. (1995) Potassium channel activation by glutathione-S-conjugates in Escherichia coli: protection against methylglyoxal is mediated by cytoplasmic acidification. Mol. Microbiol. 17, 1025-1033.

(10) Roosild, T. P., Castronovo, S., Miller, S., Li, C., Rasmussen, T., Bartlett, W., Gunasekera, B., Choe, S., and Booth, I. R. (2009) KTN (RCK) Domains Regulate $\mathrm{K}(+)$ Channels and Transporters by Controlling the Dimer-Hinge Conformation. Structure 17, 893-903.

(11) Lyngberg, L., Healy, J., Bartlett, W., Miller, S., Conway, S. J., Booth, I. R., and Rasmussen, T. (2011) KefF, the Regulatory Subunit of the Potassium Efflux System KefC, Shows Quinone Oxidoreductase Activity. J. Bacteriol. 193, 4925-4932.

(12) Healy, J., Ekkerman, S., Pliotas, C., Richard, M., Bartlett, W., Grayer, S. C., Morris, G. M., Miller, S., Booth, I. R., Conway, S. J., and Rasmussen, T. (2014) Understanding the structural requirements for activators of the Kef bacterial potassium efflux system. Biochemistry 53, $1982-1992$

(13) Roosild, T. P., Miller, S., Booth, I. R., and Choe, S. (2002) A mechanism of regulating transmembrane potassium flux through a ligand-mediated conformational switch. Cell 109, 781-791.

(14) Kong, C., Zeng, W., Ye, S., Chen, L., Sauer, D. B., Lam, Y., Derebe, M. G., Jiang, Y., and Aldrich, R. (2012) Distinct gating mechanisms revealed by the structures of a multi-ligand gated $\mathrm{K}+$ channel. eLife 1 , e00184.

(15) Li, Y., Berke, I., Chen, L., and Jiang, Y. (2007) Gating and Inward Rectifying Properties of the MthK K+ Channel with and without the Gating Ring. J. Gen. Physiol. 129, 109-120.

(16) Roosild, T. P., Castronovo, S., Healy, J., Miller, S., Pliotas, C., Rasmussen, T., Bartlett, W., Conway, S. J., and Booth, I. R. (2010) Mechanism of Ligand- Gated Potassium Efflux in Bacterial Pathogens. Proc. Natl. Acad. Sci. U. S. A. 107, 19784-19789.

(17) Krissinel, E., and Henrick, K. (2007) Inference of macromolecular assemblies from crystalline state. J. Mol. Biol. 372, 774-797.

(18) Kondrat, F. D. L., Struwe, W. B., and Benesch, J. L. P. (2015) Native mass spectrometry: towards high-throughput structural proteomics. Methods Mol. Biol. 1261, 349-371.

(19) Niesen, F. H., Berglund, H., and Vedadi, M. (2007) The use of differential scanning fluorimetry to detect ligand interactions that promote protein stability. Nat. Protoc. 2, 2212-2221.

(20) Holdgate, G. A., and Ward, W. (2005) Measurements of binding thermodynamics in drug discovery. Drug Discovery Today 10, 15431550.

(21) Elliott, T. S., Slowey, A., Ye, Y., and Conway, S. J. (2012) The use of phosphate bioisosteres in medicinal chemistry and chemical biology. MedChem Comm 3, 735-751.

(22) Bennett, B. D., Kimball, E. H., Gao, M., Osterhout, R., Van Dien, S. J., and Rabinowitz, J. D. (2009) Absolute metabolite concentrations and implied enzyme active site occupancy in Escherichia coli. Nat. Chem. Biol. 5, 593-599.

(23) Saint Girons, I., Gilles, A. M., Margarita, D., Michelson, S., Monnot, M., Fermandjian, S., Danchin, A., and Barzu, O. (1987) Structural and catalytic characteristics of Escherichia coli adenylate kinase. J. Biol. Chem. 262, 622-629.

(24) Kröning, N., Willenborg, M., Tholema, N., Hänelt, I., Schmid, R., and Bakker, E. P. (2007) ATP binding to the KTN/RCK subunit KtrA from the $\mathrm{K}+$-uptake system KtrAB of Vibrio alginolyticus: its role in the formation of the KtrAB complex and its requirement in vivo. J. Biol. Chem. 282, 14018-14027.

(25) Healy, J., Rasmussen, T., Miller, S., Booth, I. R., and Conway, S. J. (2016) The photochemical thiol-ene reaction as a versatile method for 
the synthesis of glutathione S-conjugates targeting the bacterial potassium efflux system Kef. Org. Chem. Front. 3, 439-446.

(26) Lowry, O. H., Rosebrough, N. J., Farr, A. L., and Randall, R. J.

(1951) Protein Measurement with the Folin Phenol Reagent. J. Biol. Chem. 193, 265-275.

(27) Aguilar, J. A., Nilsson, M., Bodenhausen, G., and Morris, G. A. (2012) Spin echo NMR spectra without J modulation. Chem. Commun. $48,811-813$.

(28) Chen, L., Wang, J., Zhang, Y.-Y., Yan, S. F., Neumann, D., Schlattner, U., Wang, Z.-X., and Wu, J.-W. (2012) AMP-activated protein kinase undergoes nucleotide-dependent conformational changes. Nat. Struct. Mol. Biol. 19, 716-718. 